\title{
Rating Migration and Bond Valuation: Decomposing Rating Migration Matrices from Market Data via Default Probability Term Structures
}

\author{
Brian BARNARD*
}

University of Johannesburg, South Africa

\begin{abstract}
The study builds on previous research that decomposes rating category default probability term structures from rating category interest rate term structures, and proposes a method to decompose rating migration matrices from market data, via decomposed default probability term structures. To investigate the power and accuracy of the proposed method, it was examined to what extent an existing, known rating migration matrix could again be surfaced by the method. Overall, the results are more than satisfactory, and the method promises to be accurate. Although not considered here, the main objective is the application of the method to market data. The outcome should be insightful in itself, and can be used to evaluate historical rating migration matrices commonly devised by rating agencies, and to form a better understanding of the default probability term structures embedded in market data.
\end{abstract}

Keywords: Default Probability, Default Risk, Credit Risk, Rating Migration, Bond Valuation, Optimization

JEL Classification: G32, G12

\section{Introduction}

\subsection{The Factors Impacting Bond Valuation}

The extent by which credit risk explain bond premiums is a predominant topic in bond valuation research. A number of authors conclude that it only accounts for a small fraction of bond premiums (Huang and Huang, 2012; Geske and Delianedis, 2001; Elton et al, 2001).

The predominant factors affecting bond prices are listed as risk free rates, taxes, jumps, liquidity,

\footnotetext{
${ }^{*}$ Corresponding Author:

Brian Barnard, Wits Business School, University of Johannesburg, Johannesburg, South Africa

Article History:

Received 23 May 2017 | Accepted 13 September 2017 | Available Online 23 September 2017

Cite Reference:

Barnard, B., 2017. Rating Migration and Bond Valuation: Decomposing Rating Migration Matrices from Market Data via Default Probability Term Structures. Expert Journal of Finance, 5, pp. 49-72.
} 
market risk factors, issue traits, equity volatility, market risk, systematic risk, and macroeconomic risk factors (Houweling et al, 2005; Geske and Delianedis, 2001; Elton et al, 2004; Elton et al, 2001; Grandes and Peter, 2005; Delianedis and Geske, 2003; Campbell and Taksler, 2003; Collin-Dufresne et al 2001; Athanassakos and Carayannopoulos, 2001; Fama and French, 1993; Merton, 1974).

A number of studies also look at credit rating migration risk, or simply credit migration risk. Das and Tufano (1995) state investors are exposed to three risks: interest rate risk, changes in credit risk caused by changes in the credit rating of the issuer of the debt, and changes in credit risk caused by changes in spreads on the debt, even when ratings have not changed. Altman (1996) examines the expected spread change and cost implication due to credit rating migration. In the context of portfolios, Fei et al (2012) note that risk models generally predict for each asset in the portfolio, the corresponding probability of default (PD), exposure at default (EAD) and loss given default (LGD). Similarly, Kadam and Lenk (2008) note different estimates for risk capital, derived from loss distributions, which they quantify as Value-at-Risk (VAR) and Expected Loss (EL) for the portfolio at hand. Jarrow et al (1997) models the impact in forward rates - and thus bond value due to credit rating jumps.

Delianedis and Geske (2003) note that default probabilities and changes in expected default frequencies are important to both the structure and pricing of credit derivatives. All corporate issuers have some positive probability of default. This default probability should change continuously with changes in the firm's stock price and thus its leverage. The value of most fixed income securities is typically inversely related to the probability of default. Investors are concerned about changes in the value of their fixed income securities due to changes in the probability of default, even though the actual default seldom occurs. In fact, fixed income investors may be more concerned with changes in the perceived credit quality of their bond holdings than with actual default. Rating migrations, which offer one reflection of changes in perceived quality of bonds, occur much more frequently than defaults.

Foss (1995) specifically differentiates between credit risk and default risk. He notes that the terms default risk and credit risk are often used interchangeably; however, they are not one and the same. Default risk is defined as the risk that the issuer of a fixed-income security will be unable to make timely payments of interest or principal. This risk, diversified over a portfolio of equally rated securities, leads to an expected default loss. Many of the initial studies on risks and returns focus on historical default rates and losses. Although these studies provide valuable insight, default rates and default losses, in isolation, are not paramount. Credit risk is defined as the risk that the perceived credit quality of an issuer will change, although default is not necessarily a certain event. Increased credit risk is reflected in a widening of the yield spread. Credit and default risk are correlated because credit deterioration is almost always a precursor to eventual default; even in the most drastic cases, however, until default actually occurs, the potential for recovery or stabilization cannot be totally discounted. In line with this, Manzoni (2004) makes the point that, while several studies model default and bankruptcy events, no empirical work directly models the probability of a bond having its rating revised. He points out the traditional default mode of thinking of most financial institutions, leading to a consensus view of transitions as non-fundamental economic events.

\subsection{Credit Default Swaps and Bond Valuation}

Norden and Weber (2009) argue that CDS should reflect pure issuer default risk, and no facility or issue specific risk, making these instruments a potentially ideal benchmark for measuring and pricing credit risk. According to Blanco et al (2005), CDSs are an upper bound on the price of credit risk (while credit spreads form a lower bound). Benkert (2004) argues that CDS premia represent primarily a price of default risk, and are in this respect similar to bond spreads. Consequently, CDS premia and bond spreads should be driven by the same factors. A number of studies (Benkert, 2004; Ericsson et al, 2009) indeed consider the same factors of bond valuation to explain CDS premiums. Weistroffer et al (2009) mention that rating agencies use information derived from CDS prices to calculate market implied ratings.

\subsection{Default Probability}

Zhu (2006) states that, in general, measures of credit risk consist of three building blocks: probability of default (PD), loss given default (LGD) and correlation between PD and LGD. In order to model default risk, Athanassakos and Carayannopoulos (2001), consider three proxy variables: i) credit rating, which captures the effect of both the probability of default and the recovery rate; ii) time to maturity; iii) the existence of a sinking fund. Both of the latter two proxies should be related to the probability of default.

Grandes and Peter (2005) note that, when government bonds are not truly risk-free, particularly in an emerging market, the corporate yield spread above an equivalent government bond yield does not reflect corporate default risk, even after controlling for all other factors. It merely reflects corporate default risk in 
excess of sovereign default risk. They model corporate default probability as the probability that the firm defaults given that the sovereign does not default, plus the probability that the firm defaults given that the sovereign has defaulted.

Campbell and Taksler (2003) note that the literature distinguishes between structural and reduced form models. The authors note that "In structural models, a firm is assumed to default when the value of its liabilities exceeds the value of its assets, in which case bondholders assume control of the company in exchange for its residual value. Reduced form models, by contrast, assume exogenous stochastic processes for the default probability and the recovery rate. The added flexibility of the reduced-form approach allows default risk to play a somewhat greater role in the pricing of corporate bonds."

Merton (1974) shows that for a given maturity, the risk of default varies directly with the variance of the returns on the firm value. In this context, the business cycle and economic environment impact both the level of the risk free rate and the variance of returns on the firm value.

Huang and Huang (2012) consider a credit risk model with a counter-cyclical market risk premium to capture the effects of business cycles on credit risk premia. Secondly, they introduce an analytically tractable jump-diffusion structural credit risk model to capture the effects on credit risk premia of certain future states with both high default risks and abnormally high stochastic discount factors. The second mechanism is distinctly different from the first mechanism. In the model with jumps in asset values, the jumps are unpredictable and there is no time variation in market risk premia.

In line with reduced form models, Elton et al (2001) develop marginal default probabilities from a rating transition matrix employing the assumption that the rating transition process is stationary and Markovian. In year one, the marginal probability of default can be determined directly from the transition matrix and default vector, and is, for each rating class, the proportion of defaults in year one. To obtain subsequent year defaults, they first use the transition matrix to calculate the ratings going into a given year for any bond starting with a particular rating in the previous year. The defaults of that year are then the proportion in each rating class multiplied by the probability that a bond in that class defaults by year end. They find that the marginal probability of default increases for the high-rated debt and decreases for the low-rated debt. This occurs because bonds change rating classes over time.

A number of studies use bond valuation models - both structural and reduced form - to note the extent by which market prices can be modelled, and to note the magnitude of default probability as bond valuation factor (Eom et al, 2004; Elton et al, 2001; Huang and Huang, 2012; Geske and Delianedis, 2001; CollinDufresne et al, 2001).

Fei et al (2012) note a credit rating is a financial indicator of an obligor's level of creditworthiness. Given the relationship between credit ratings and default probability or credit quality, Kumar and Haynes (2003) discuss rating methodology and list the key factors considered as: i) business analysis (industry risk; market position; operating efficiency; legal position), ii) financial analysis (accounting quality; earnings protection; adequacy of cash flows; financial flexibility; interest and tax sensitivity), and iii) management evaluation (track record of management; evaluation of capacity to overcome adverse situations; goals, philosophy and strategies). They find that financial parameters reflect, to a significant extent, the subjective and objective factors used by an expert while rating a debt obligation, with hidden relationships between the financial parameters and associated expert rating.

A number of authors examine the timeliness, accuracy and actual information content of credit rating agencies' ratings (Hines et al, 1975; Ederington and Goh, 1998; Amato and Furfine, 2004). Amato and Furfine (2004) mention that rating agencies insist that their ratings should be interpreted as ordinal rankings of default risk that are valid at all points in time, rather than absolute measures of default probability that are constant through time. Delianedis and Geske (2003) note that rating agencies regularly measure the historical default frequency of corporate issuers. While these historical default frequencies are interesting, they are not forwardlooking. Option models can provide a forward-looking, risk neutral default probability. Chan and Jegadeesh (2004) point to evidence that agency ratings may not be accurate in a timely fashion.

Studies like Wang (2004) attempt to model default ratings, and studies like Hines et al (1975), Kaplan and Urwitz (1979), Belkaoui (1980) and Chan and Jegadeesh (2004) statistically model bond ratings. This may provide alternative default probability estimates, as structural models also do, relative to the credit ratings of credit rating agencies, but must still be translated to default probability term structures, in a similar way credit agencies' ratings are translated.

Also, a number of studies quantify credit ratings as proxies of credit quality in terms of spread (Foss, 1995; Kaplan and Urwitz, 1979; Cantor et al, 1997; Perraudin and Taylor, 2004; Chan and Jegadeesh, 2004). 


\subsection{Default Probability Term Structures}

Altman (1989) notes that analysts have concentrated their efforts on measuring the default rate for finite periods of time - for example, one year - and then averaging the annual rates for longer periods.

Elton (1999) argues that realized returns are a very poor measure of expected returns and that information surprises highly influence a number of factors in an asset pricing model. He believes that developing better measures of expected return and alternative ways of testing asset pricing theories that do not require using realized returns have a much higher payoff than any additional development of statistical tests that continue to rely on realized returns as a proxy for expected returns. He argues that either there are information surprises that are so large or that a sequence of these surprises is correlated so that the cumulative effect is so large that they have a significant permanent effect on the realized mean. Furthermore, these surprises can dominate the estimate of mean returns and be sufficiently large that they are still a dominant influence as the observation interval increases. Thus, the difference between expected and realized returns is viewed as a mixture of two distributions, one with standard properties and the other that more closely resembles a jump process.

Duffie and Singleton (1999) state that, because of the possibility of sudden changes in perceptions of credit quality, particularly among low-quality issues such as Brady bonds, one may wish to allow for surprise jumps in default probability.

Nelson and Siegel (1987) state the range of shapes generally associated with interest rate term structures: monotonic, humped, and S shaped. Related to this, a number of studies consider the relationship or correlation between default probability, interest rates, and the state of the economy (Benkert, 2004; Duffie and Singleton, 1999; Das and Tufano, 1995; Huang and Huang, 2012; Athanassakos and Carayannopoulos, 2001; Amato and Furfine, 2004; Delianedis and Geske, 2003; Longstaff and Schwartz, 1995; Kim et al 1993; Campbell and Taksler, 2003; Lando and Skødeberg, 2002; Hamilton and Cantor, 2004).

Benkert (2004) argue that corporate defaults occur more often during economic downturns than during boom phases, and the occurrence of a recession may cause a decline in credit quality that leads to more defaults in the future. According to this line of reasoning, the compensation for default risk would rise. Duffie and Singleton (1999) note strong evidence that hazard rates for default of corporate bonds vary with the business cycle. Equally, recovery data also exhibit a pronounced cyclical component. Das and Tufano (1995) allowed recovery to vary over time so as to induce a non-zero correlation between credit spreads and the riskless term structure. However, for computational tractability they maintained the assumption of independence of the hazard rate (default rate) and risk-free rate.

Huang and Huang (2012) argue that a credit risk premium is required by investors because the uncertainty of default loss should be systematic - bondholders are more likely to suffer default losses in bad states of the economy. Moreover, precisely because of the tendency for default events to cluster in the worst states of the economy, the credit risk premium can be potentially very large. Athanassakos and Carayannopoulos (2001) note that yield spreads are greater during recessions than during recoveries, and also point to the link between the behaviour of yield spreads to the shape of the term structure, as a proxy of the business cycle. They confirm the typical direct relationship between default risk and yield spreads, and show that the impact of the business cycle (macro-economy) on the yield spread of a corporate bond depends on the industry sector to which the issuer of the bond belongs. The inflation rate should be directly related to yield spreads, since during inflationary periods investors may require higher risk premia from their investments in corporate bonds.

Athanassakos and Carayannopoulos (2001) use the change in the shape of the term structure of interest rates - represented by the quarterly change in the difference between the 20 -year treasury rates and the three month t-bill rates - as a proxy for the business cycle, since much research in the past has linked the shape of the treasury term structure to future variations in the business cycle. A steepening term structure is a typical result of robust economic growth and lower short term interest rates and reflects a general belief in a more robust economic future. The opposite is true when the term structure is flattening or turns negatively sloped. Therefore, the particular proxy should be negatively related to yield spreads. Finally, the annual rate of change in the industrial production index should be negatively related to yield spreads since increased economic activity will bolster investors' confidence in the corporate sector, and lead to a reduction in the risk premia demanded for investment in corporate bonds.

Amato and Furfine (2004) argue that financial market participants behave as if risk is countercyclical, e.g. at its highest during economic downturns. Empirical models, too, tend to indicate a rise in risk during recessions. There is a relationship between the correlation of default rates and loss in the event of default and the business cycle. Models that assume independence of default probabilities and loss given default will tend to underestimate the probability of severe losses during economic downturns. They delineate the empirical 
significance of the pro-cyclicality of credit quality changes by showing that estimated credit losses are much higher in a contraction relative to an expansion.

Longstaff and Schwartz (1995) argue that the corporate yield spread should vary inversely with the benchmark treasury yield, and find evidence to support this. Kim et al (1993) show that default risk is not particularly sensitive to the volatility of interest rates but is sensitive to interest rate expectations. Campbell and Taksler (2003) note idiosyncratic volatility can move very differently from market-wide volatility. Movements in idiosyncratic risk are more persistent than movements in market risk. Lando and Skødeberg (2002) note that it is likely that macroeconomic variables or other indicators of the business cycle influence rating intensities.

A number of studies model default probability term structures as instantaneous stochastic processes (Das and Tufano, 1995; Duffee, 1999; Jarrow et al, 2002) . For example, Duffee (1999) uses the extended Kalman filter to fit yields on bonds issued by individual investment-grade firms to a model of instantaneous default risk. Das and Tufano (1995) and Jarrow et al (1997) model default risk as Markov chains or trees. Jarrow and Turnbull (1995) exogenously specify a stochastic process for the evolution of the default-free term structure and the term structure for risky debt.

Duffee (1999) argues that at each instant there is some probability that a firm defaults on its obligations. Both this probability and the recovery rate in the event of default may vary stochastically through time. The stochastic processes determine the price of the credit risk. Although these processes are not formally linked to an organization's asset value, it can be assumed there is some underlying relation. The instantaneous probability that a given firm defaults on its obligated bond payments follow a translated single-factor squareroot diffusion process, with a modification that allows the default process to be correlated with the factors driving the default-free term structure. There are a number of factors other than default risk that drive a discrepancy between corporate and Treasury bond prices, such as liquidity differences, state taxes, and special repo rates. Here, all of these factors are substituted into a stochastic process called a default risk process. Default risk is negatively correlated with the default-free interest rates. For a typical firm, the instantaneous risk of default has a lower bound that exceeds zero. In other words, even if an organization's financial health dramatically improves, the model implies that yield spreads on the organization's bonds remain positive.

Duffee (1999) first models the price of a risk-free bond as given by the expectation, under the equivalent martingale measure, of the cumulative discount rate between $t$ and $\mathrm{T}$. The discount rate follows a stochastic process - the sum of a constant, and two factors that follow independent square-root stochastic processes. He then models the adjusted discount rate for bond issues that can default, relative to risk-free bonds. This setup is designed to capture three important empirical features of corporate bond yield spreads. The most obvious is that the spreads are stochastic, fluctuating with the financial health of the firm. The second feature is that yield spreads for very high-quality firms are positive, even at the short end of the yield curve. This fact suggests that regardless of how healthy a firm may seem, there is some level below which yield spreads cannot fall. The third feature is that yield spreads, especially spreads for lower quality bonds, appear to be systematically related to variations in the default-free term structure.

Houweling and Vorst (2005) note reduced form models that use time series estimation to model the hazard rate stochastically, typically as a Vasicek or CIR process. Also, other reduced form models use crosssectional estimation and consider either constant or stochastic hazard rates, where the stochastic process is chosen in such a way that the survival probability curve is known analytically. Houweling and Vorst (2005) follow an intermediate approach by using a deterministic function of time to maturity. This specification facilitates parameter estimation, while still allowing for time-dependency. They model the integrated hazard function as a polynomial function of time to maturity, with three degrees - linear, quadratic and cubic.

Das and Tufano (1995) choose to make recovery rates correlated with the term structure of interest rates. This results in a model wherein credit spreads are correlated with interest rates, as is evidenced in practice. In the Jarrow-Lando-Turnbull model credit spreads change only when credit ratings change, whereas in the debt markets it is found that credit spreads change even when ratings have not changed. Injecting stochastic recovery rates into the model provides this extra feature.

In the context of default probability term structures, credit migration and credit migration matrices should also be mentioned.

A number of studies examine the stochastic processes associated with rating transitions (Frydman and Schuermann, 2008; Lando and Skødeberg, 2002; Hamilton and Cantor, 2004; Altman, 1996). Altman and Rijken (2004) investigate the through-the-cycle methodology that agencies use, in the context of bond valuation, and rating timeliness and rating stability.

Nickell et al (2000) use Moody's data from 1970 to 1997 to examine the dependence of ratings transition probabilities on industry, country and stage of the business cycle using an ordered probit approach, 
and they find that the "business cycle dimension is the most important in explaining variation of these transition probabilities". They point out that rating transition matrices vary according to the stage of the business cycle, the industry of the obligor and the length of time that has elapsed since the issuance of the bond. Kadam and Lenk (2008) identified strong differences in rating migration behaviour between issuers of different industry sectors and countries.

Bangia et al (2002) argue that "credit migration matrices provide specific linkage between underlying macroeconomic conditions and asset quality". Credit migration matrices characterize the expected changes in credit quality of obligors. Total volatility (risk) is composed of a systematic and an idiosyncratic component. Because ratings are a reflection of a firm's asset quality and distance to default, a reasonable definition of "systematic" is the state of the economy. They find distinct differences between the U.S. expansion and contraction transition matrices. The most striking difference between expansion and contraction matrices are the downgrading and especially the default probabilities that increase significantly in contractions. Overall, these results reveal that migration probabilities are more stable in contractions than they are on average, supporting the existence of two distinct economic regimes. The rating universe should develop differently in contraction periods compared to expansion times.

The straightforward application of these matrices however would normally be restricted to situations where the future state of the economy over the transition horizon under consideration is assumed to be known. The condition of the economy unmistakably is one of the real drivers of systematic credit risk, especially as lower credit classes are substantially more delicate to macro-economic factors. Consequently it ought to be integrated into credit risk modelling whenever possible, otherwise the downward potential of high-yield portfolios in contractions might be underestimated. Modern credit risk models represent different industries only through different term structures, yet not through industry dependent transition matrices.

Fei et al (2012) proposes an approach to estimate credit rating migration risk that controls for the business-cycle evolution during the relevant time horizon in order to ensure adequate capital buffers both in good and bad times. The approach allows the default risk associated with a given credit rating to change as the economy moves through different points in the business cycle. They mention a body of research linking portfolio credit risk with macroeconomic factors showing, for instance, that default risk tends to increase during economic downturns. Their premise is that point-in-time methodologies that account for business cycles should provide more realistic credit risk measures than through-the-cycle models that smooth out transitory fluctuations (perceived as random noise) in economic fundamentals.

\subsection{Decomposing Default Probabilities from Market Data}

\subsubsection{Decomposing Rating Migration Matrices from Market Data}

Taken from Barnard (2017a), equation 1 states the reduced form model of Duffie and Singleton (1999), adapted for coupon paying bonds. Equation 1 has two components, a coupon paying component associated with non-default outcomes, and a recovery component associated with default outcomes.

In the equation, $V$ is the price or value of the risk-bearing bond; $M$ is the number of coupons of the bond, including par; $C_{m}$ is the coupon of the bond on coupon date $m ; R$ is the recovery of par value; $r_{t_{m}}^{r f}$ and $t_{m}$ are the risk-free spot rate and time value, respectively, associated with coupon date $m ; h_{n}$ is the default probability of interval $n$, conditional on no default prior to interval $n ; P_{m}$ is the cumulative non-default probability of interval $m ; J_{m}$ is the number of probability intervals for which the possibility of default is considered up to coupon date $m ; J_{M}$ is the number of probability intervals considered up to maturity.

For coupon paying bonds, it is convenient to consider $J_{m}$ and $J_{M}$ to be equal to $m$ and $M$. For example, the third coupon may have three probability intervals leading up to it. For zero-coupon bonds, $M$ is equal to 1 , and $J_{M}$ may be greater than $M$, with $J_{m}$ not necessarily corresponding with $m$; a regular coupon interval may still be considered though to ensure a timely and consistent consideration of default. A five-year zero coupon bond will have only one coupon, but can have up to ten probability intervals leading up to it, if semi-annual probability intervals are used. 


$$
\begin{gathered}
V=\sum_{m=1}^{M}\left(\prod_{n=1}^{J_{m}}\left(1-h_{n}\right) e^{-r_{t_{m}}^{r f} t_{m}} C_{m}\right)+\sum_{j=1}^{J_{M}}\left(\prod_{n=1}^{j-1}\left(1-h_{n}\right) h_{j} e^{-r_{t_{j}}^{r f} t_{j}} R\right) \\
\prod_{n=1}^{j-1}\left(1-h_{n}\right)=1 ; j-1<1 \\
P_{m \mid m-1}=\prod_{n=1}^{P_{m}}=\prod_{n=1}^{J_{m}}\left(1-h_{n}\right) \\
=\prod_{n=1}^{J_{m}-1}\left(1-h_{n}\right)-\prod_{n=1}^{J_{m}}\left(1-h_{n}\right)=\prod_{J_{m}}^{J_{m}-1}\left(1-h_{n}\right)\left(1-\left(1-h_{J_{m}}\right)\right) \\
V=\sum_{m=1}^{M} P_{m} e^{-r_{t_{m}}^{r f} t_{m}} C_{m}+\sum_{j=1}^{J_{M}} P_{j \mid j-1} e^{-r_{t_{j}}^{r f} t_{j}} R
\end{gathered}
$$

Although not explicitly stated by them, equation 2 delineates the default probability term structure implemented by Elton et al (2001). They subsequently substitute this into a reduced form model similar to equation 1.

cat $^{\text {non-default }}$ are all non-default rating categories; $I_{\text {Path }}$ is the intensity or propensity of path or tree Path $_{m}$ that leads up to interval $m$; similarly, $I_{j}^{P a t h}$ is the path intensity or propensity of path $j ; I_{m}^{\text {cat }}{ }_{n}$ is the intensity or propensity of rating category $n$ in interval $m$; $P a t h_{m}^{\text {default }}$ is the number of default paths of (up to) interval $m$; $P_{a t h} h_{m}^{\text {non-default }}$ is the number of non-default paths of interval $m$; contrary to a default path, a non-default path can not and does not end up in default over its length or run; $P_{a t h}^{\text {non-default }}$ is the number of non-default paths that migrate to - end with - category $k$ in interval $m ; P_{b_{(n-1)} \rightarrow b_{n}}^{m i g \mid n}$ is the probability of migration from rating $b_{n-1}$ in interval $n-1$ to rating $b_{n}$ in interval $n ; P_{k \rightarrow n}^{m i g \mid m}$ is the probability of migration from category $k$ to category $n$ in interval $m ; P_{k \rightarrow \text { default }}^{m i g \mid m}$ is the probability of category $k$ migrating to default status in interval $m ; h_{n}$ is again the default probability of interval $n$, conditional on no default prior to interval $n$.

$$
\begin{aligned}
& I_{\text {Path }_{m}}=\prod_{n=1}^{J_{m}} P_{b_{(n-1)}}^{m i g \mid n} b_{n}
\end{aligned}
$$

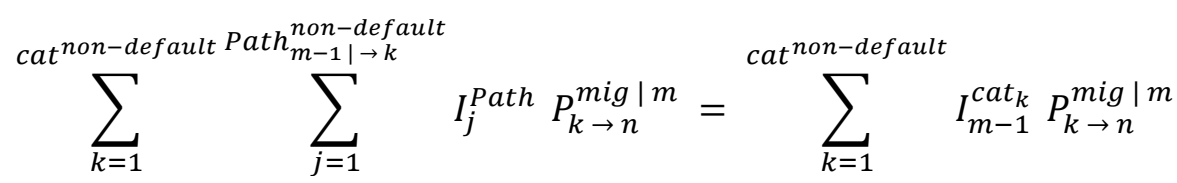

$$
\begin{aligned}
& \prod_{n=1}^{m}\left(1-h_{n}\right)=\sum_{n=1}^{\text {Path }_{m}^{\text {non-default }}} I_{n}^{\text {Path }}=\sum_{n=1}^{\text {cat }} I_{m}^{\text {non-default }} I^{\text {cat }}{ }_{n} \\
& \prod_{n=1}^{m-1}\left(1-h_{n}\right) h_{m}=\sum_{\substack{k=1 \\
\text { cat }}}^{\text {can }{ }^{\text {non-default }}} \sum_{j=1}^{\text {non-default Path }} I_{j-1 \mid \rightarrow k}^{\text {non-default }} I_{j}^{\text {Path }} P_{k \rightarrow \text { default }}^{\text {mig } \mid m} \\
& =\sum_{k=1}^{\text {cat }} I_{m-1}^{\text {nan-default }} P_{k \rightarrow \text { default }}^{\text {mig } \mid m}
\end{aligned}
$$




$$
\begin{array}{r}
h_{n}=1-\left(\prod_{m=1}^{n}\left(1-h_{m}\right) / \prod_{m=1}^{n-1}\left(1-h_{m}\right)\right) \\
=\left(\sum_{k=1}^{c a t^{\text {non-default }}} I_{n-1}^{\text {cat }} P_{k \rightarrow \text { default }}^{\text {mig } \mid n}\right) /\left(\prod_{m=1}^{n-1}\left(1-h_{m}\right)\right)
\end{array}
$$

Equation 3 allows the recovery rate to depend on the rating category the bond is in when it defaults. Moving from equation 1.4 to equation 3.1 is further explained by equation set $2 . R_{m}^{n}$ is the recovery of par value of rating category $n$ in interval $m$.

$$
V=\sum_{m=1}^{M} P_{m} e^{-r_{t_{m}}^{r f} t_{m}} C_{m}+\sum_{j=1}^{J_{M}} \sum_{n=1}^{\text {cat non-default }} I_{j-1}^{\text {cat }} P_{n \rightarrow \text { default }}^{\text {mig } j} e^{-r_{t_{j}}^{r f} t_{j}} R_{j}^{n}
$$

Equation set 4 contains the optimization problem to extract the market rating migration matrix from market prices. Any proper rating migration matrix that satisfy the constraints could serve as initial solution. The migration probabilities of the rating migration matrix form the coefficients of the optimization problem and are adjusted and selected as part of the optimization. A number of constraints can be stipulated, varying in principality or importance: For each rating category, the sum of the probabilities of migrating from the particular category to any other non-default category, plus the probability of default of the category should equal 1 (equation 4.b). For each rating category, any probability of migrating to any other non-default category, as well as the probability of default of that particular category should be greater than or equal to zero (equation 4.c). For each rating category with a rating category preceding it, the particular category's probability of default should be equal to or higher than that of the category preceding it (equation 4.d). For each rating category, the probability of migrating to rating category $n$ should be equal to or greater than the probability of migrating to rating category $n+1$, if rating category $n$ succeeds the rating category; and for each rating category, the probability of migrating to rating category $n$ should be equal to or greater than the probability of migrating to rating category $n-1$, if rating category $n$ preceeds the rating category (equation 4.e).

$V_{n}^{\text {market }}$ and $V_{n}^{\text {model }}$ are the market and modelled bond value of bond $n ; V_{n}^{\text {market } \mid k}$ and $V_{n}^{\text {model } \mid k}$ are the market and modelled bond value of bond $n$ with rating category $k ; N$ is the total number of bonds included in the sample; $N_{k}$ is the total number of sample bonds of rating category $k$; cat ${ }^{\text {non-default }}$ refers to all the non-default rating categories; $P_{m \rightarrow n}^{\mathrm{mig}}$ is the probability of migrating from category $m$ to $n$; $P_{\text {cat }}^{\text {default }}$ is the probability of default for category $m$.

$$
\begin{aligned}
& \text { minimize } \sum_{\substack{n=1 \\
\text { cat }}}^{N}\left(V_{n}^{\text {man-default }} N_{k} \text { (arket }-V_{n}^{\text {model }}\right)^{2} \\
& \text { minimize } \sum_{k=1}^{\text {cat }} \sum_{n=1}^{\text {non-default }} \sum_{k}^{N_{k}}\left(V_{n}^{\text {market } \mid k}-V_{n}^{\text {model } \mid k}\right)^{2}
\end{aligned}
$$

Subject to:

$$
\begin{aligned}
& \sum_{n=1}^{\text {cat }}{ }^{\text {non-default }} P_{m \rightarrow n}^{\text {mig }}+P_{\text {cat }}^{\text {default }}=1 ; m \in\left\{1, \ldots, \text { cat }^{\text {non-default }}\right\} \\
& \sum_{n=1}^{\text {cat }}{ }^{\text {non-default }} P_{m \rightarrow n}^{\text {mig }} \geq 0 ; P_{\text {cat }}^{\text {default }} \geq 0 ; m \in\left\{1, \ldots, \text { cat }^{\text {non-default }}\right\} \\
& P_{\text {cat }_{m}}^{\text {default }} \geq P_{\text {cat }_{m-1}}^{\text {default }} ; m \in\left\{2, \ldots, \text { cat }^{\text {non-default }}\right\} \\
& P_{n \rightarrow n-x}^{m i g} \geq P_{n \rightarrow n-x-1}^{m i g} \\
& P_{n \rightarrow n+x}^{\text {mig }} \geq P_{n \rightarrow n+x+1}^{\text {mig }} \\
& n \in\left(1, \ldots \text { cat }^{\text {non-default }}\right) \\
& n-x \leq \text { cat }^{\text {non-default }} n-x-1 \geq 1 \\
& n+x+1 \leq \text { cat }^{\text {non-default }} ; n+x \geq 1
\end{aligned}
$$




\section{Solution}

\subsubsection{Delta-Coefficients, Partial Derivatives Measurement, and the Optimization Problem}

Equation 4.b forms an equality constraint - for any rating category, the sum of the probabilities of migrating from the particular category to any other non-default category, plus the probability of default of the category should at all times equal 1. A principal concern is the integrity of partial derivatives measured during optimization, in the wake of this equality constraint. Given that partial derivatives are measured by small coefficient steps during optimization, it may essentially imply non-conformance to or a relaxation or violation of the equality constraint, and it may in turn imply the partial derivatives measured are distorted, particularly given the sensitivity of their measurement. If the equality constraint must be met not to distort the measurement of partial derivatives of the migration probability coefficients, it implies the basic assumption of coefficient independence does not hold. Thus, it becomes a question of whether it is permissible to assume coefficient independence during measurement of partial derivatives as part of optimization.

In light of this, it is suggested that, instead of modelling and optimizing migration probability coefficients directly, delta coefficients are rather used to model and optimize rating category migration probabilities. For this purpose, all rating migrations are sub-classified as primary or $\mathrm{x}$-to-x migration, or secondary or $\mathrm{x}$-to-y migration. Primary or $\mathrm{x}$-to-x migration involves the particular rating category maintaining its rating; secondary or $\mathrm{x}$-to-y migration involves the rating category migrating to a different rating category, including default. A particular delta coefficient then depicts the net movement or change between the primary or x-to-x migration and the corresponding secondary or $\mathrm{x}$-to-y migration of the associated rating category. Therefore, only $x-$ to-y migration probabilities are assigned delta coefficients. The intermediate or end probability of any $x$-to-y migration equals its initial probability - taken from the initial solution - plus its delta coefficient (equation 5.a). x-to-x migration probabilities are not assigned delta coefficients directly, but obtain their intermediate and end probabilities from the sum of the x-to-y migration delta coefficients (equation 5.b), that can also be seen as depicting net movement out of the primary migration probability coefficient. In other words, according to equation 5 , a positive (negative) delta coefficient implies $\mathrm{x}$-to-x migration increases (decreases), and the corresponding x-to-y migration decreases (increases) by the same quantity. This way, the mentioned equality constraint of equation $4 . \mathrm{b}$ is met at all times, also when measuring partial derivatives.

In equation set $5, P_{m \rightarrow n}^{\text {mig } \mid \text { start }}$ is the initial rating migration probability; $P_{m \rightarrow n}^{\text {mig } \mid \text { end }}$ is the end rating migration probability; $\Delta P_{m \rightarrow n}^{m i g}$ is the rating migration delta between primary rating category $m$ and secondary rating category $n ; P_{m \rightarrow n}^{m i g}$ and $P_{m \rightarrow \text { default }}^{m i g}$ depict x-to-y migration of rating category $m ; P_{m \rightarrow m}^{m i g}$ depict x-to-x migration of rating category $\mathrm{m}$.

$$
\begin{aligned}
& P_{m \rightarrow n}^{m i g \mid \text { end }}=P_{m \rightarrow n}^{\text {mig } \mid \text { start }}-\Delta P_{m \rightarrow n}^{m i g} ; n \neq m ; n \neq \text { default } ; n \in \text { [rating categories] } \\
& P_{m \rightarrow \text { default }}^{\text {mig } \mid \text { end }}=P_{m \rightarrow \text { default }}^{\text {mig } \mid \text { start }}-\Delta P_{m \rightarrow \text { default }}^{\text {mig }} \\
& P_{m \rightarrow n}^{m i g \mid \text { end }}=P_{m \rightarrow n}^{\text {mig } \mid \text { start }}-\Delta P_{m \rightarrow n}^{\text {mig }} ; n \neq m ; n \in[\text { rating categories; default }] \\
& \left.P_{m \rightarrow m}^{m i g \mid \text { end }}=P_{m \rightarrow m}^{m i g \mid \text { start }}+\sum_{n}^{N} \Delta P_{m \rightarrow n}^{m i g} ; n \neq m ; n \in \text { [rating categories; default }\right]
\end{aligned}
$$

Equation 6 rewrites the original optimization problem in terms of delta coefficients.

$$
\begin{gathered}
\text { minimize } \sum_{n=1}^{N}\left(V_{n}^{\text {market }}-V_{n}^{\text {model }}\right)^{2} \\
\text { minimize } \sum_{k=1}^{\text {cat }} \sum_{n=1}^{\text {non-default }}\left(V_{n}^{\text {market } \mid k}-V_{n}^{\text {model } \mid k}\right)^{2}
\end{gathered}
$$

Subject to:

$$
\begin{array}{cc}
P_{m \rightarrow m}^{\text {mig } \mid \text { start }}+\sum_{n}^{N} P_{m \rightarrow n}^{\text {mig } \mid \text { start }}=1 & n \neq m ; n \in \text { [ratingcategories; default }] \\
P_{m \rightarrow n}^{\text {mig|start }}-\Delta P_{m \rightarrow n}^{m i g} \geq 0 ; & P_{m \rightarrow n}^{\text {mig } \mid \text { start }}-\Delta P_{m \rightarrow n}^{m i g} \leq 1 \\
P_{m \rightarrow m}^{\text {mig|start }}+\sum_{n}^{N} \Delta P_{m \rightarrow n}^{m i g} \geq 0 ; & P_{m \rightarrow m}^{\text {mig } \mid \text { start }}+\sum_{n}^{N} \Delta P_{m \rightarrow n}^{\text {mig }} \leq 1 \\
P_{m \rightarrow \text { default }}^{\text {mig|start }}-\Delta P_{m \rightarrow \text { default }}^{\text {mig }} \geq P_{(m-1) \rightarrow \text { default }}^{\text {mig|start }}-\Delta P_{(m-1) \rightarrow \text { default }}^{\text {mig }}
\end{array}
$$




$$
\begin{gathered}
P_{m \rightarrow n}^{\text {mig|start }}-\Delta P_{m \rightarrow n}^{m i g} \geq P_{m \rightarrow n+1}^{\text {mig } \mid \text { start }}-\Delta P_{m \rightarrow n+1}^{m i g} \\
P_{m \rightarrow n}^{\text {mig|start }}-\Delta P_{m \rightarrow n}^{\text {mig }} \geq P_{m \rightarrow n-1}^{\text {mig } \mid \text { start }}-\Delta P_{m \rightarrow n-1}^{\text {mig }} \\
P_{m \rightarrow m}^{\text {mig|start }}+\sum_{n}^{N} \Delta P_{m \rightarrow n}^{m i g} \geq P_{m \rightarrow m+1}^{\text {mig } \mid \text { start }}-\Delta P_{m \rightarrow m+1}^{\text {mig }} \\
P_{m \rightarrow m}^{\text {mig|start }}+\sum_{n}^{N} \Delta P_{m \rightarrow n}^{\text {mig }} \geq P_{m \rightarrow m-1}^{\text {mig } \mid \text { start }}-\Delta P_{m \rightarrow m-1}^{\text {mig }}
\end{gathered}
$$

Equation 6 uses delta coefficients to solve the impact of the rating migration probability sum equality constraint of equation 4.b on the measurement of partial derivatives during optimization. However, there is one drawback. For any net transfer of migration probability between secondary rating categories to take place, it must pass through the primary rating category. At the same time, all partial derivatives would always be measured via or against primary rating migration, given that all delta coefficients are stipulated in terms of net flow of migration probability between the secondary rating categories and the primary rating category. As an example, given the rating migration matrix entry of rating category $\mathrm{BBB}$, and assuming that a shift between the probability of migration from rating category $\mathrm{BBB}$ to rating category $\mathrm{BB}$, and the probability of migration from rating category BBB to rating category A would improve the solution, the shift can generally only occur by two sub-shifts - a shift between the probability of migration from rating category BBB to rating category $\mathrm{BB}$, and the probability of migration from rating category $\mathrm{BBB}$ to rating category $\mathrm{BBB}$, and a shift between the probability of migration from rating category $\mathrm{BBB}$ to rating category $\mathrm{A}$, and the probability of migration from rating category BBB to rating category BBB. At present, the partial derivatives of this type of flow cannot and are not measured directly, and are only indirectly represented by the partial derivatives of the existing coefficients.

It is possible to also include delta coefficients between secondary rating categories to permit direct migration probability flows between secondary rating categories, and to change the way the partial derivatives corresponding to these flows or changes are measured. The drawback of this is that it tends to over-correct the problem. A number of additional coefficients are introduced, and the change in the measurement of partial derivatives allows redundant flows between rating category migration probabilities. Shifting migration probability between rating categories - between the primary rating category and secondary rating categories for instance - can now follow a number of paths, and are not limited to one path anymore, and measured partial derivatives may easily encourage redundant flows. Redundant flows refers to exchange, change or flow of migration probability, more than what is necessary to reach a certain desired distribution or spread of migration probability. The problem is not in the end distribution of migration probability across the primary and secondary rating categories, but in the way it is reached. Redundant flows equally implies a distortion of the measurement of partial derivatives, and also impacts the optimization solution.

Figure 1 demonstrates the issue of redundant flows. Assume 4 rating categories, and that figure 1 depicts a rating category entry in a rating migration matrix. Further assume that, for simplicity, a migration probability transfer of 0.1 between the primary rating category and each secondary rating category optimizes the solution. The second part of figure 1 reaches the same result, albeit with a redundant flow between secondary rating category 1 and 2 . It illustrates that additional delta coefficients between secondary rating categories does not necessarily solve the underlying issue of the impact of coefficients on partial derivatives measurement and in turn the solution.

One method to overcome redundant flows is to stipulate all possible, non-redundant flows, and to then utilize a corresponding number of sub-optimization problems, with each sub-optimization problem only including the delta coefficients that matches the possible, non-redundant flow it represents. The suboptimization problems are solved sequentially, and the best result is taken for the next iteration. The process is terminated the moment a better solution can no longer be found. Figure 2 shows the number of suboptimization problems together with their delta coefficient specification for a 3 rating category problem, that would cover all possible rating migration probability transfers, and simultaneously exclude the possibility of redundant flows. 

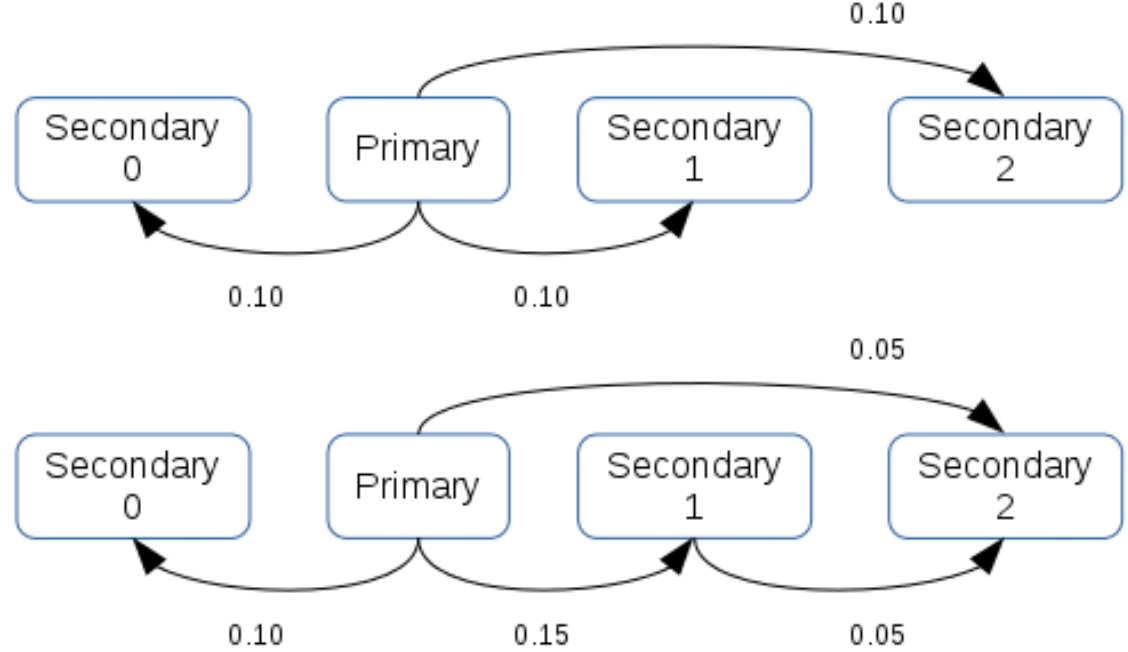

Figure 1. Redundant flows between the migration probabilities of a rating category rating migration matrix entry
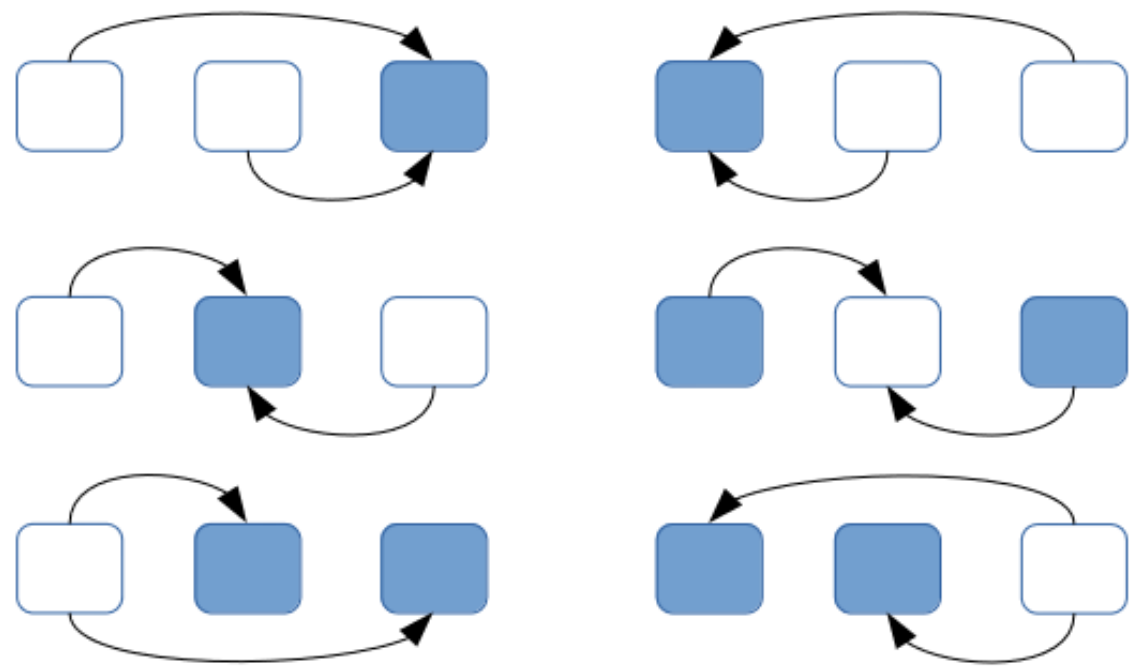

Figure 2. Sub-optimization problem count and delta coefficient specification for a 3 rating category problem

\subsubsection{Decomposing Default Probability Term Structures from Market Data}

Equation 4 and 6 may still be complex, computationally expensive, and may still be improved upon, in particular by sourcing better initial solutions. As illustrated by Barnard (2017b), one option may be to first decompose default probability term structures per rating category. This can then be used to decompose or work towards a rating migration matrix. Equation 7 stipulates the optimization problem to decompose rating category default probability term structures from market data. The constraints are that each of the interval default probabilities must be greater than or equal to 0 , and less than or equal to 1 (equation 7.b). Also, a constraint is added to limit the resulting structure variance below a stipulated ceiling (equation 7.c). This method of decomposition is outlined by Barnard (2016a) and Barnard (2016b). Structure variance is measured as the rate of change of interval default probability. Modelled bond value is based on the reduced form model of equation 1, and the decomposed interval default probabilities are substituted into that equation.

Again, $V_{n}^{\text {market } \mid k}$ and $V_{n}^{\text {model } \mid k}$ are the market and modelled bond value of bond $n$ with rating category $k ; N_{k}$ is the total number of sample bonds of rating category $k ; h_{m}$ is the interval default probability of interval $m ; M$ is the total number of intervals; $C^{v}$ is the specified variance ceiling.

$$
\text { minimize } \sum_{n=1}^{N_{k}}\left(V_{n}^{\text {market } \mid k}-V_{n}^{\text {model } \mid k}\right)^{2}
$$

Subject to:

$$
h_{m} \geq 0
$$

$$
h_{m} \leq 1
$$




$$
\sum_{m=1}^{M-1}\left(h_{m+1}-h_{m}\right)^{2} \leq C^{v}
$$

As part of the optimization, market bond value - as opposed to modelled bond value - can also be based on a market based interest rate term structure instead - an interest rate term structure decomposed from market data. Instead of its quoted price, the market value of a bond is taken to be the resultant value when discounting the bond against the market based interest rate term structure. This assumes the decomposed market interest rate term structure ideally represents the market outlook, and this renders bond issues' residual modelling error equal to zero. The benefit of this is that it reduces idiosyncratic bond value error, thereby simplifying the problem. This also shifts the focus from merely a portfolio of bonds to an interest rate term structure instead, such that the objective may be expressed as decomposing the corresponding default probability term structure of an interest rate term structure, and vice versa, rather than decomposing the default probability term structure of a portfolio.

Furthermore, when market bond value is based on a decomposed interest rate term structure, and the number of issues are sufficient, and adequately spaced in terms of maturity, it is also possible to calculate a default probability term structure by means of a sequential (bootstrapping) method that iteratively seeks the next interval default probability that minimizes modelled issue value error. The mechanics of the sequential method is easy to follow when considering an issue with such a maturity that it is only affected by one interval default probability - in this case, the default probability term structure (applicable to the issue) only spans one interval, and can be calculated through iterative searching. When ordering issues according to maturity, each subsequent issue will then also have only one outstanding interval default probability, if it adopts the default probability term structure of the preceding issues and intervals.

\subsubsection{Decomposing Rating Migration Matrices from Default Probability Term Structures}

The following stipulates the method to decompose rating migration matrices from default probability term structures, rather than from bond issue value. Decomposing from default probability term structures instead, may imply smoother data, and that the default probabilities of the rating categories are already known - according to equation 2, first interval default probability equals the default probability of the rating category (Barnard, 2017a; Barnard, 2017b). This in turn implies it is only necessary to decompose the non-default migration probabilities of the rating migration matrix.

Equation set 8 contains the general optimization problem. The optimization problem optimizes a solution rating migration matrix, and interval default probabilities are modelled from the solution rating migration matrix by means of equation 2 . The constraints included are: a) for each rating category, the sum of the probabilities of migrating from the particular category to any other non-default category, plus the probability of default of the category should equal 1 (equation 8.b, corresponding to equation 4.b); b) for each rating category, any probability of migrating to any other non-default category, as well as the probability of default of that particular category should be greater than or equal to zero (equation 8.c and equation 8.e, corresponding to equation 4.c); c) for each rating category, the probability of migrating to rating category $n$ should be equal to or greater than the probability of migrating to rating category $n+1$, if rating category $n$ succeeds the rating category; and for each rating category, the probability of migrating to rating category $n$ should be equal to or greater than the probability of migrating to rating category $n-1$, if rating category $n$ preceeds the rating category (equation 8.d, corresponding to equation 4.e); d) for each rating category with a rating category preceding it, the particular category's probability of default should be equal to or higher than that of the category preceding it (equation 8.f, corresponding to equation 4.d). Equation 8 would face the same issues discussed under section 1.5.2, and should be implemented with delta coefficients, as outlined under section 1.5.2 and equation 6.

$N_{k}$ is the number of intervals of rating category $k ; h_{n}^{\text {market } \mid k}$ and $h_{n}^{\text {model } \mid k}$ are the decomposed market and modelled inteval default probabilities of interval $n$ and rating category $k$, respectively; $P_{m \rightarrow n}^{m i g}$ is the probability of rating category mmigrating to rating category $n ; P_{c a t}^{\text {default }}$ is the probability of rating category $m$ defaulting.

$$
\operatorname{minimize} \sum_{n=1}^{N_{k}}\left(h_{n}^{\text {market } \mid k}-h_{n}^{\text {model } \mid k}\right)^{2}
$$

Subject to: 


$$
\begin{aligned}
& \sum_{n=1}^{\text {cat }}{ }^{\text {non-default }} P_{m \rightarrow n}^{\text {mig }}+P_{\text {cat }}^{\text {default }}=1 ; m \in\left\{1, \ldots, \text { cat }^{\text {non-default }}\right\} \\
& \sum_{n=1}^{\text {cat }}{ }^{\text {non-default }} P_{m \rightarrow n}^{\text {mig }} \geq 0 ; m \in\left\{1, \ldots, \text { cat }^{\text {non-default }}\right\} \\
& P_{n \rightarrow n-x}^{\operatorname{mig}} \geq P_{n \rightarrow n-x-1}^{m i g} \\
& P_{n \rightarrow n+x}^{\text {mig }} \geq P_{n \rightarrow n+x+1}^{\text {mig }} \\
& n \in\left(1, \ldots \text { cat }^{\text {non-default }}\right) \\
& n-x \leq \text { cat }^{\text {non-default }} ; n-x-1 \geq 1 \\
& n+x+1 \leq \text { cat }^{\text {non-default }} ; n+x \geq 1 \\
& P_{\text {cat }_{m}}^{\text {default }} \geq 0 \\
& P_{\text {cat }_{m}}^{\text {default }} \geq P_{\text {cat }_{m-1}}^{\text {default }} ; m \in\left\{2, \ldots, \text { cat }^{\text {non-default }}\right\}
\end{aligned}
$$

The overall optimization is conducted in two steps or procedures. The first step builds an initial solution rating migration matrix, by sequentially optimizing the rating migration matrix entries of individual rating categories, and by gradually increasing the percentage by which the rating migration matrix is applied when determining the interval intensities and thus the interval default probabilities of a rating category. An initial multiplier of $0(0 \%)$ is used, and incremented to $1(100 \%)$ through a step increment of $0.05(5 \%)$. The effect of this is that rating categories initially ignore the rating migration matrix entries of other rating categories, and gradually adjust their rating migration matrix entries to that of the other rating categories. It helps to ease the inter-dependency between rating categories - the dependency of a rating category on other rating category rating migration matrix entries are controlled by the multiplier. The updated rating migration entries of each rating category are stored in a temporary buffer for the next iteration. The first step implements the optimization problem of equation 8 , through delta-coefficients, and with additional delta-coefficients realized by sub-optimization problems to prevent redundant flows, as outlined under section 1.5.2.

The outcome of the above step is a valid rating migration matrix that is partially optimized. To further optimize this initial solution, two different optimization problems are used. Both optimization problems build on equation 8 . The first type simultaneously optimize the rating migration matrix entries of all rating categories. It uses delta-coefficients, but only utilizes the primary delta-coefficient set, and does not include delta-coefficients for secondary rating categories, and the corresponding additional sub-optimization problems. The second type sequentially optimize the rating migration matrix entries of individual rating categories. Additional delta-coefficients are used for secondary rating categories, through additional sub-optimization problems. It essentially corresponds to the method used to build the initial solution rating migration matrix. The only difference is that it does not use a multiplier - when optimizing the rating migration matrix entry of a rating category, the rating migration matrix entries of other rating categories are not factored, but used as is.

The first optimization process attempts to simultaneously optimize rating migration matrix entries of rating categories against each other. The second optimization process attempts to optimize the rating migration matrix entry of an individual rating category against the existing rating migration matrix entries of other rating categories. The outcomes are not the same. The solution is further optimized and improved by iterating between the optimization processes. After optimizing the rating migration matrix entry of an individual rating category against the rating migration matrix entries of the other rating categories, it becomes feasible again to simultaneously optimize the rating migration matrix entries of all rating categories against each other, and vice versa.

\section{Methodology}

The study examines the power and accuracy of the proposed method to decompose rating migration matrices from market data, via decomposed default probability term structures. An existing, known rating migration matrix is utilized, and it is investigated to what extent the original rating migration matrix can again be surfaced by the method, when fed relevant data. The rating migration matrix naturally provides a reference default probability term structure per rating category (equation 2 ). The rating category default probability term structures, but not the original rating migration matrix, are provided to the method. In addition, the method is provided with a portfolio of bonds, a risk-free term structure, and rating category recovery rates. From this the value of the bonds can be calculated (equation 1), and the market value of the bonds are assumed equal to the calculated value. In turn, the value of the bonds are used to decompose an interest rate term structure for each rating category included in the bond portfolio, and a default probability term structure is decomposed for each rating category from the corresponding rating category interest rate term structures. The decomposed rating category default probability term structures should and do correspond with the reference rating category default probability term structures. From the rating category default probability term structures, the default probability 
of each rating category is obtained, such that it is only necessary to decompose the non-default rating migration probabilities of the rating migration matrix.

Seven principal credit ratings are considered - [AAA, AA, A, BBB, BB, B, CCC]. The study uses a rating migration matrix from Elton et al (2001). The rating migration matrix is slightly adapted where it violates some of the constraints mentioned as part of equation 4 and 8 . Table 2 and table 3 show the original and adapted rating migration matrix, respectively. In all cases that bond value is modelled, equation 1 is used to calculate the value of the bonds. Recovery rates are taken from Elton et al (2001). Table 1 shows the recovery rates used. The risk-free rate used is taken from Elton et al (2001) and Huang and Huang (2012). An artificial portfolio of bonds is used, and the coupons of the bonds are set to 7.5. For each rating category, ten intervals are considered, and the maturity of the issues are such that one issue matures per interval. Thus, 10 issues are used per rating category, and 70 issues are used overall.

The actual decomposition of the rating category default probability term structures from the price data of the bonds, via the rating category interest rate term structures, is not conducted here, but taken from Barnard (2017b).

A simple barrier method is utilized to implement all optimization problems. However, an algorithm is used to iteratively switch between optimization equations, and the best result per iteration is used as the initial solution of the next iteration. Equation 9 notes the optimization equations used, in extension to the conventional least-squares problem expression of equation 8.a, for example. Nevertheless, all optimization equation results are still converted to, expressed, and compared in terms of the principal least-squares problem expression. Equation 9.c and equation 8.a are identical. Equation 9.a applies a multiplier to the difference between reference and modelled values. Equation 9.b considers absolute modelling error, instead of squared modelling error, and equation 9.d and 9.e respectively penalize positive and negative modelling error more strongly.

$$
\begin{gathered}
y=\sum_{n}^{N}\left(V_{n}^{\text {market }}-V_{n}^{\text {model }}\right) / a \\
a \in\left[1,10^{5}, 10^{10}\right] \\
z=|y| \\
z=(y)^{2} \\
z=(y)^{b_{1}}+(y)^{b_{2}} \\
b \in[(4,3),(8,6)] \\
z=(y)^{b_{1}}-(y)^{b_{2}} \\
b \in[(4,3),(8,6)]
\end{gathered}
$$

Table 1. Recovery rates as percentage of par (Elton et al, 2001)

\begin{tabular}{|l|l|l|l|l|l|l|}
\hline AAA & AA & A & BBB & BB & B & CCC \\
\hline 68.34 & 59.59 & 60.63 & 49.42 & 39.05 & 37.54 & 38.02 \\
\hline
\end{tabular}

Table 2. Rating migration probability - Standard and Poor's (Elton et al, 2001)

\begin{tabular}{|l|l|l|l|l|l|l|l|l|}
\hline & AAA & AA & A & BBB & BB & B & CCC & Default \\
\hline AAA & 90.788 & 8.291 & 0.716 & 0.102 & 0.102 & 0.000 & 0.000 & 0.000 \\
\hline AA & 0.103 & 91.219 & 7.851 & 0.620 & 0.103 & 0.103 & 0.000 & 0.000 \\
\hline A & 0.924 & 2.361 & 90.041 & 5.441 & 0.719 & 0.308 & 0.103 & 0.103 \\
\hline BBB & 0.000 & 0.318 & 5.938 & 86.947 & 5.302 & 1.166 & 0.117 & 0.212 \\
\hline BB & 0.000 & 0.110 & 0.659 & 7.692 & 80.549 & 8.791 & 0.989 & 1.209 \\
\hline B & 0.000 & 0.114 & 0.227 & 0.454 & 6.470 & 82.747 & 4.086 & 5.902 \\
\hline CCC & 0.228 & 0.000 & 0.228 & 1.251 & 2.275 & 12.856 & 60.637 & 22.526 \\
\hline Default & 0.000 & 0.000 & 0.000 & 0.000 & 0.000 & 0.000 & 0.000 & 100.000 \\
\hline
\end{tabular}


Table 3. Rating migration probability adapted from Standard and Poor's (Elton et al, 2001)

\begin{tabular}{|l|l|l|l|l|l|l|l|l|}
\hline & AAA & AA & A & BBB & BB & B & CCC & Default \\
\hline AAA & 90.789 & 8.291 & 0.716 & 0.102 & 0.102 & 0.000 & 0.000 & 0.000 \\
\hline AA & 0.103 & 91.22 & 7.851 & 0.620 & 0.103 & 0.103 & 0.000 & 0.000 \\
\hline A & 0.924 & 2.361 & 90.041 & 5.441 & 0.719 & 0.308 & 0.103 & 0.103 \\
\hline BBB & 0 & 0.318 & 5.938 & 86.947 & 5.302 & 1.166 & 0.117 & 0.212 \\
\hline BB & 0 & 0.110 & 0.659 & 7.692 & 80.550 & 8.791 & 0.989 & 1.209 \\
\hline B & 0 & 0.114 & 0.227 & 0.454 & 6.470 & 82.747 & 4.086 & 5.902 \\
\hline CCC & 0.228 & 0.228 & 0.228 & 1.251 & 2.275 & 12.856 & 60.408 & 22.526 \\
\hline Default & 0.000 & 0.000 & 0.000 & 0.000 & 0.000 & 0.000 & 0.000 & 100.000 \\
\hline
\end{tabular}

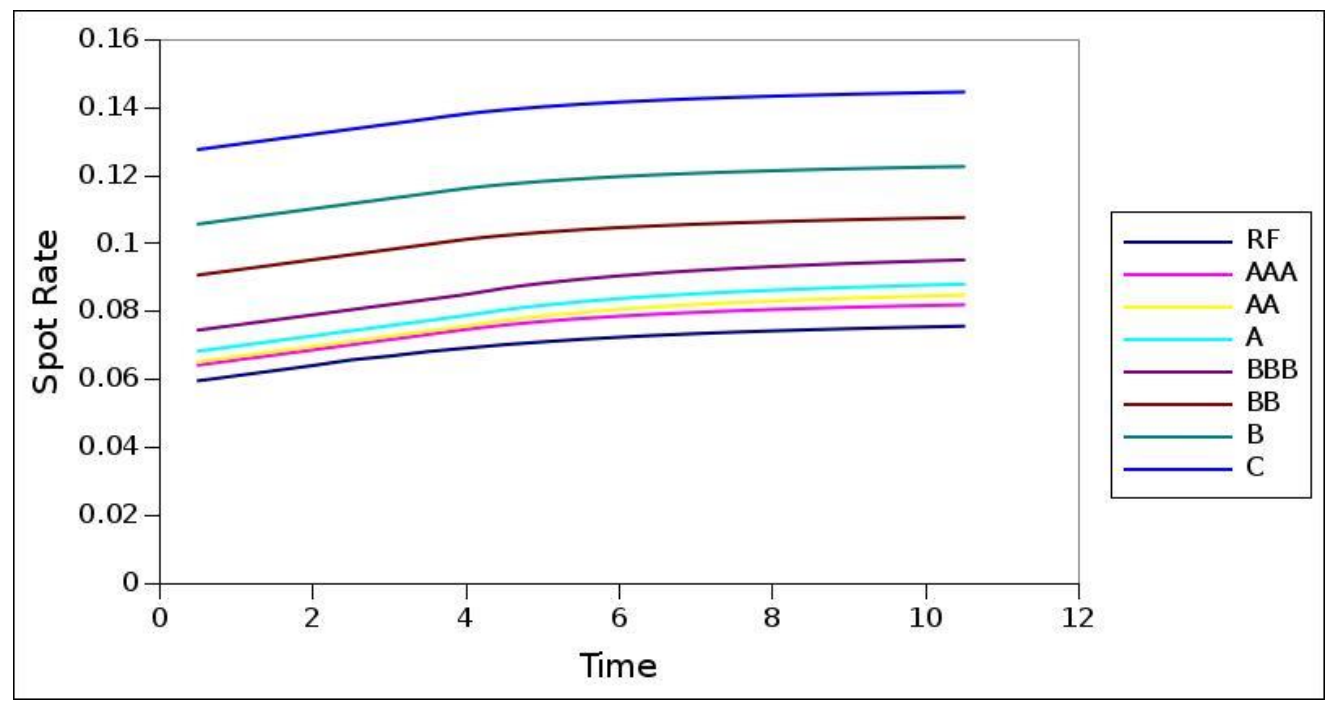

Figure 3. Risk-free and risk-bearing term structures

\section{Analysis}

The outcome of the first step that seeks to develop an applicable initial solution rating migration matrix, by sequentially optimizing individual rating category rating migration matrix entries, and iteratively incrementing the rating migration matrix multiplier, is discussed first. Because the number of steps are too many, the individual rating migration matrices corresponding to the increments are not shown. Instead, the rating migration matrix progressions of each rating category are shown in figure 4 to 10 . In the discussion below, migration probability is used to refer to the rating migration probability of a rating category rating migration matrix entry in short.

The figures show that the primary rating category of each rating category rating migration matrix entry, and thus of each figure, does not necessarily dominate, due to the multiplier factor being applied. Not all the figures commence with a strong migration probability for the primary rating category: some of these migration probabilities are below 0.4, compared to the migration probabilities of the reference rating migration matrix, which are above 0.8 on average. Neither are the extent of the volatility or changes in migration probabilities necessarily dependent on the multiplier factor - the tail of the figures experience as much volatility as the head of the figures. Both volatile and stable sections or intervals exist, over which the migration probabilities across steps or increments are rather volatile or stable, depending on the interval. The primary rating category migration probability may oscillate excessively between its initial value and terminating value. For example, figure 5 shows that the primary rating category (AA) migration probability oscillates twice between an initial value around 0.4 , and a terminating value around 0.8 . The figures show that rating categories respond to the rating migration matrix entries of other rating categories, per step, and are particularly dependent on the rating migration matrix entries of their neighbour rating categories.

Table 4 shows the terminating initial solution rating migration matrix. It has an error sum of less than 0.025. Although it may seem low, the error sum should be interpreted with caution. Table 4 shows that the rating migration matrix still significantly differ from the reference rating migration matrix of table 3 . Rating 
categories A and B stand out as their rating migration matrix entries deviate the most from the reference rating migration matrix of table 3 , particularly in terms of the primary rating category migration probability.

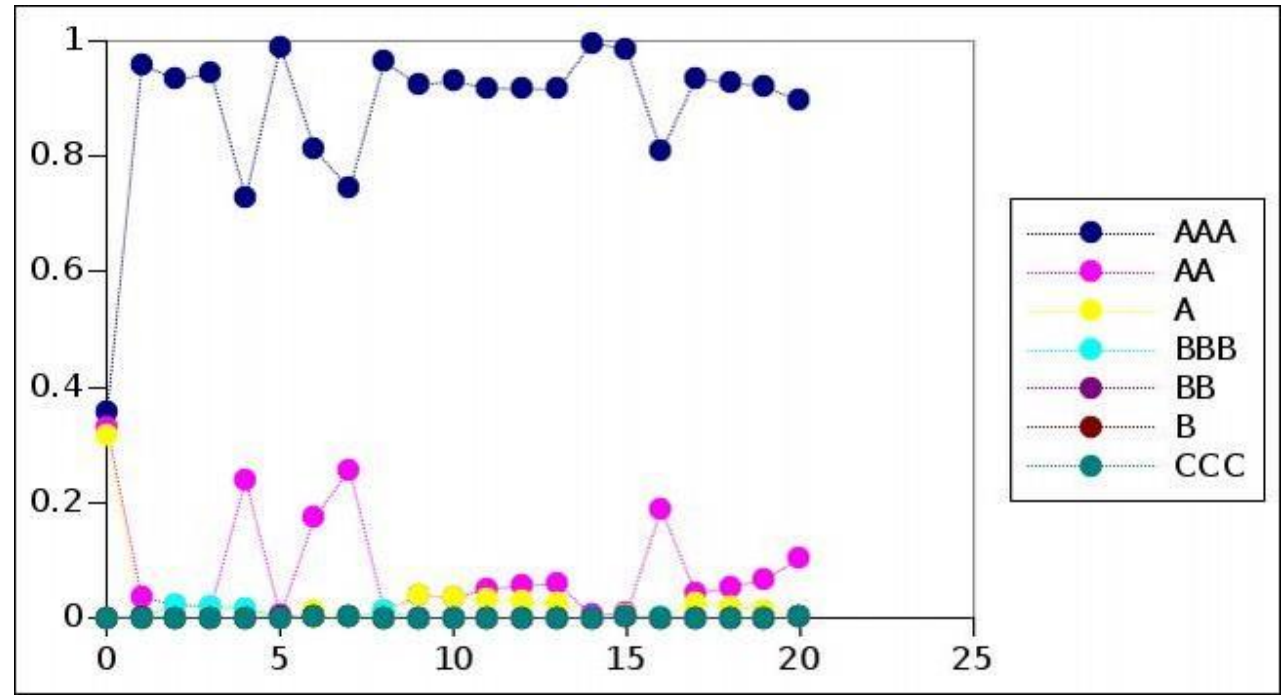

Figure 4. Rating migration matrix progression $-A A A$

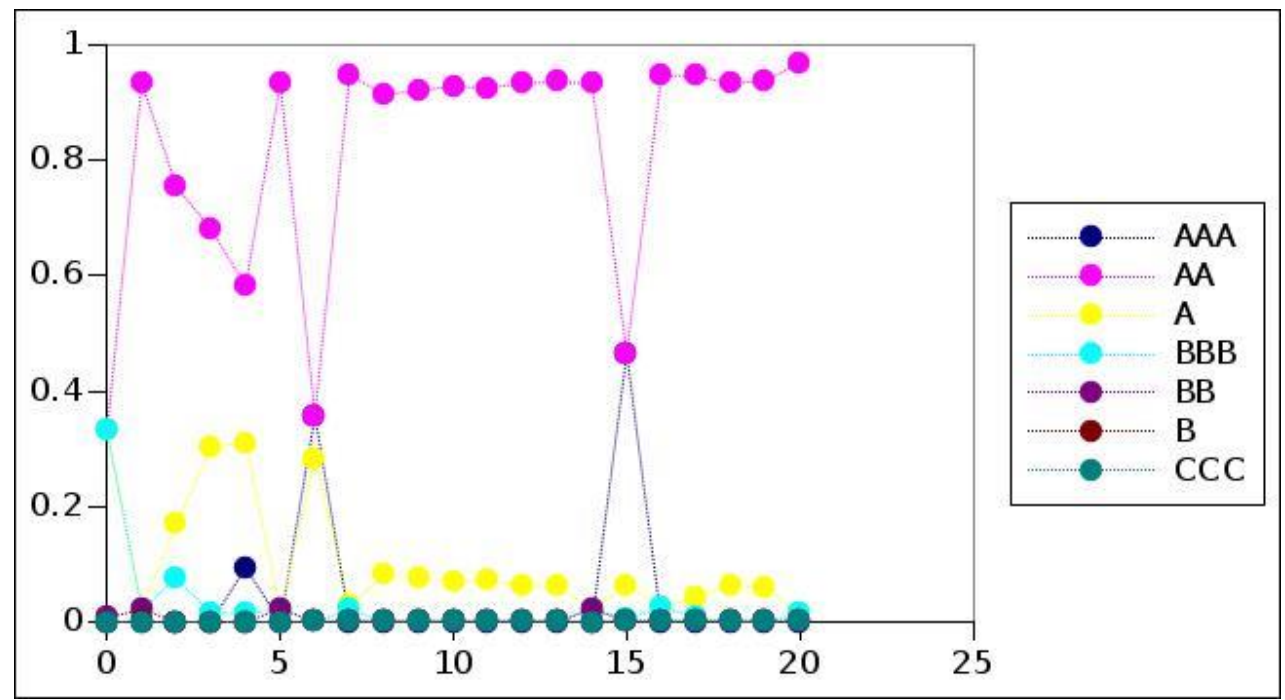

Figure 5. Rating migration matrix progression - $A A$

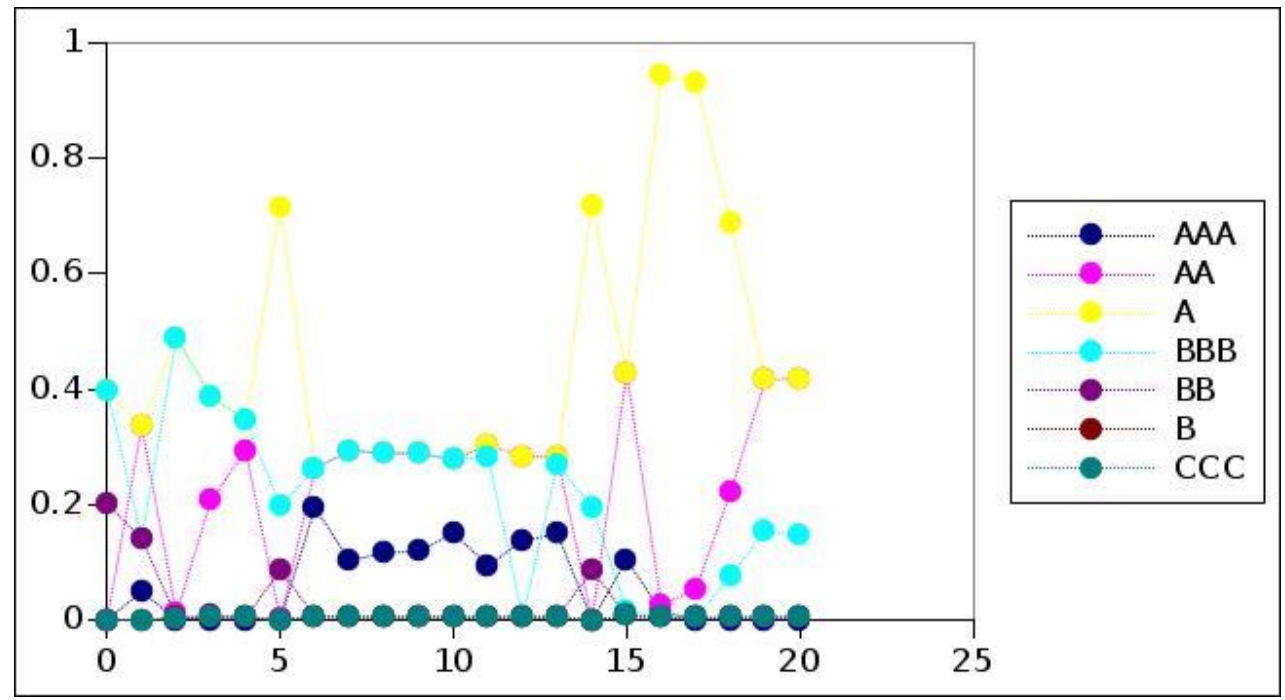

Figure 6. Rating migration matrix progression $-A$ 


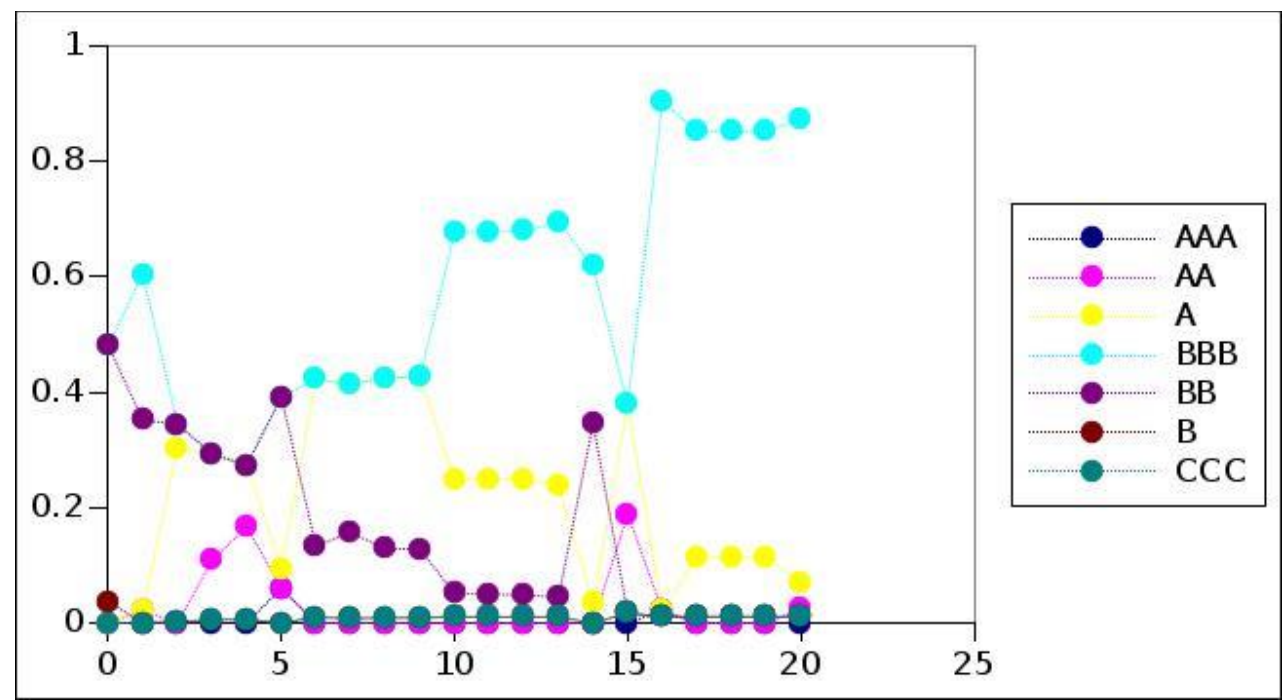

Figure 7. Rating migration matrix progression $-B B B$

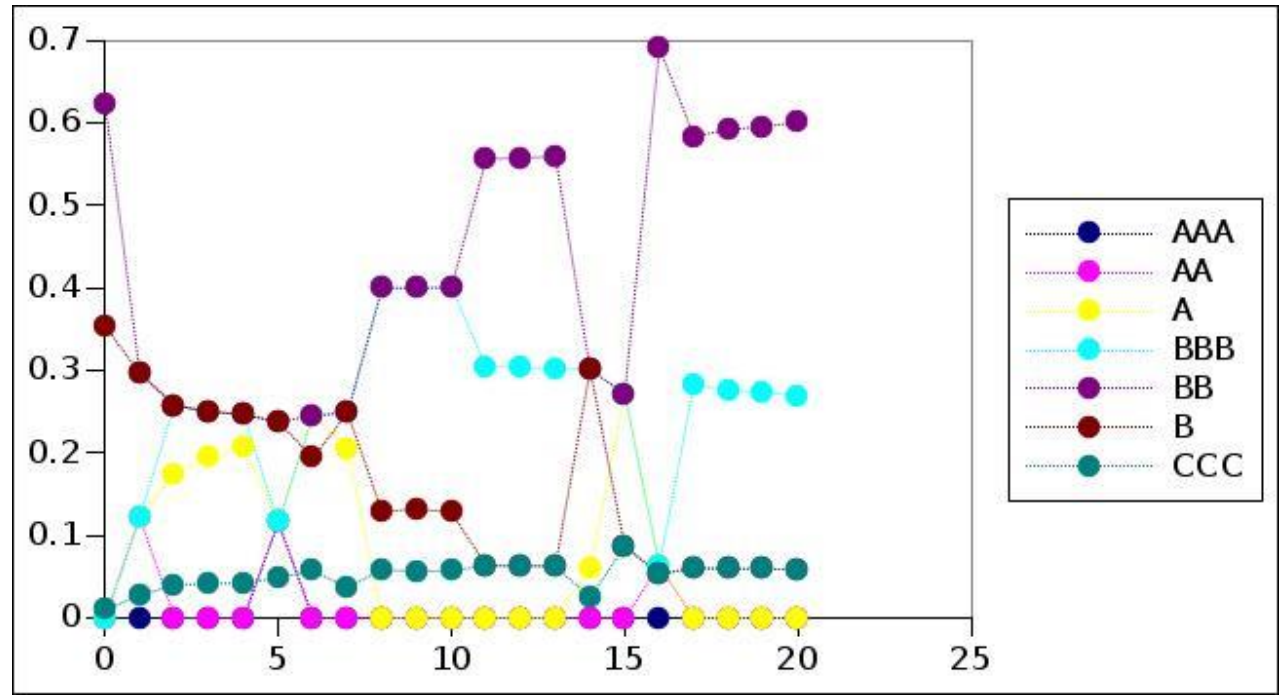

Figure 8. Rating migration matrix progression - $B B$

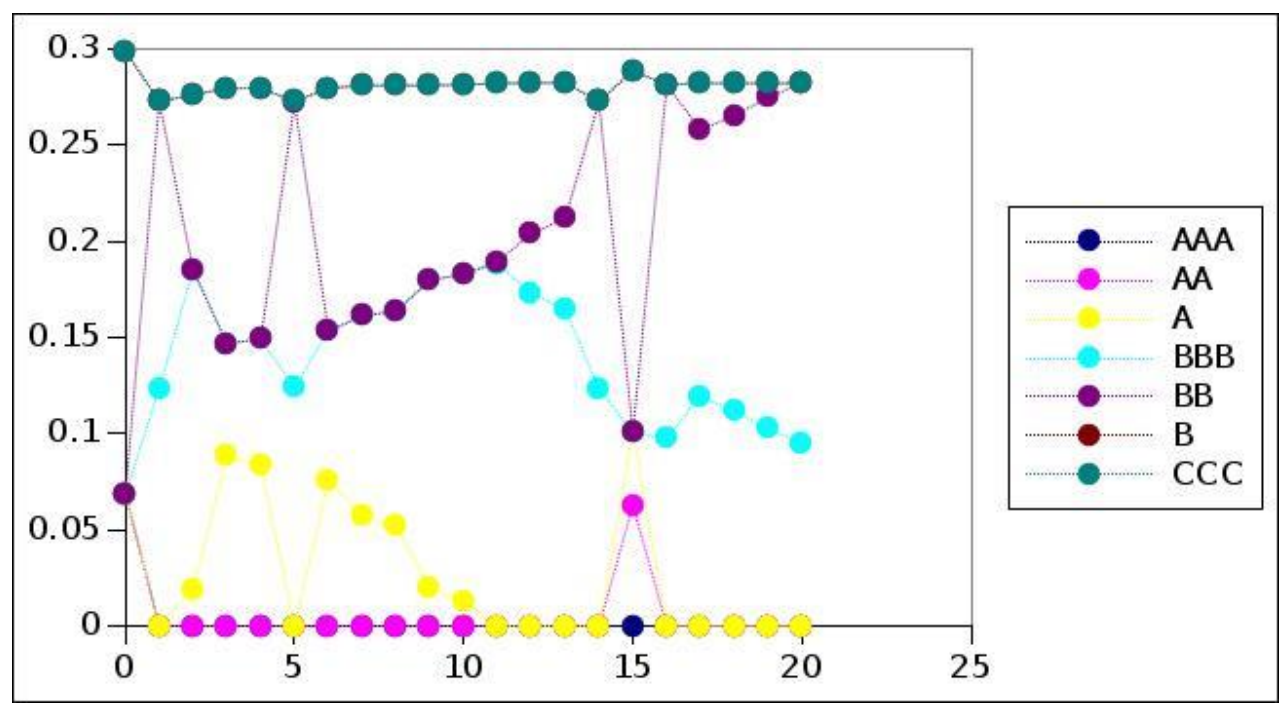

Figure 9. Rating migration matrix progression $-B$ 


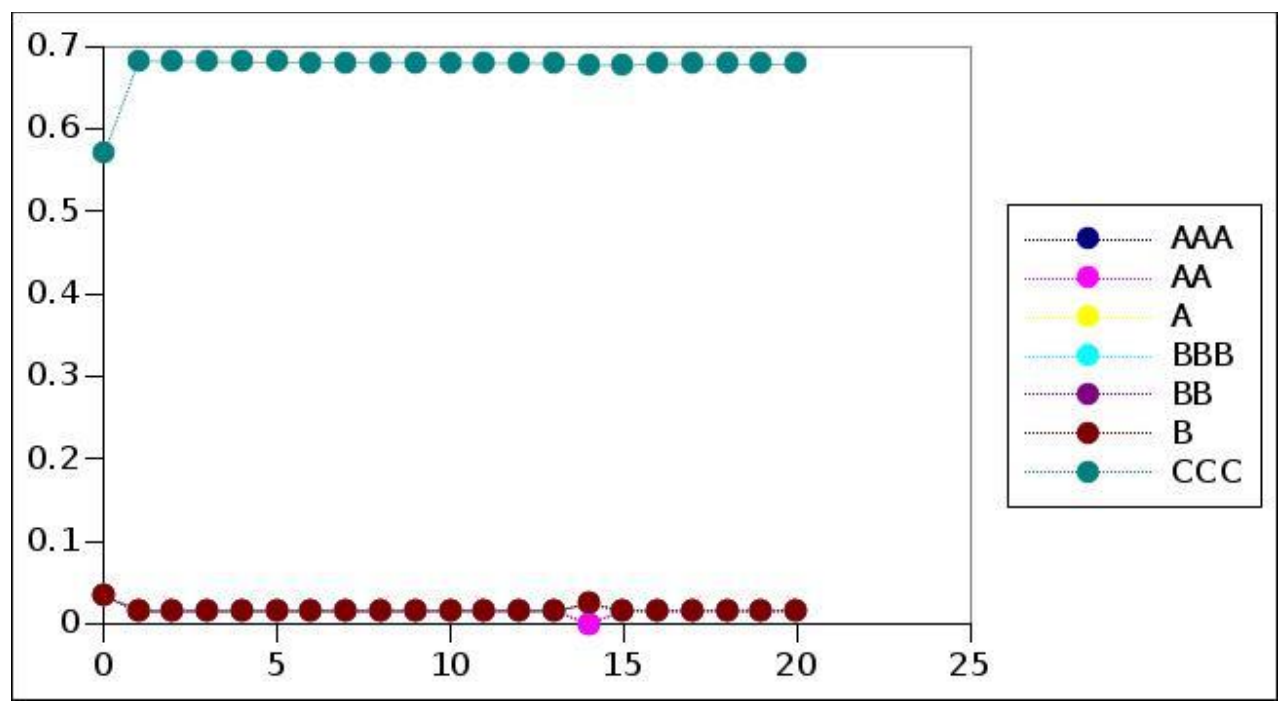

Figure 10. Rating migration matrix progression - CCC

Table 4. Initial solution rating migration matrix of step 1

\begin{tabular}{|l|l|l|l|l|l|l|l|l|}
\hline & AAA & AA & A & BBB & BB & B & CCC & Default \\
\hline AAA & $8.949 \mathrm{e}-01$ & $1.042 \mathrm{e}-01$ & $1.880 \mathrm{e}-04$ & $1.880 \mathrm{e}-04$ & $1.880 \mathrm{e}-04$ & $1.880 \mathrm{e}-04$ & $1.880 \mathrm{e}-04$ & 0.000 \\
\hline AA & $3.008 \mathrm{e}-05$ & $9.680 \mathrm{e}-01$ & $1.468 \mathrm{e}-02$ & $1.468 \mathrm{e}-02$ & $8.895 \mathrm{e}-04$ & $8.895 \mathrm{e}-04$ & $8.895 \mathrm{e}-04$ & 0.000 \\
\hline A & $3.000 \mathrm{e}-05$ & $4.185 \mathrm{e}-01$ & $4.185 \mathrm{e}-01$ & $1.474 \mathrm{e}-01$ & $4.869 \mathrm{e}-03$ & $4.869 \mathrm{e}-03$ & $4.869 \mathrm{e}-03$ & 0.103 \\
\hline BBB & $3.000 \mathrm{e}-05$ & $2.378 \mathrm{e}-02$ & $6.978 \mathrm{e}-02$ & $8.724 \mathrm{e}-01$ & $1.061 \mathrm{e}-02$ & $1.061 \mathrm{e}-02$ & $1.061 \mathrm{e}-02$ & 0.212 \\
\hline BB & $3.000 \mathrm{e}-05$ & $3.00 \mathrm{e}-05$ & $3.000 \mathrm{e}-05$ & $2.691 \mathrm{e}-01$ & $6.009 \mathrm{e}-01$ & $5.891 \mathrm{e}-02$ & $5.891 \mathrm{e}-02$ & 1.209 \\
\hline B & $3.000 \mathrm{e}-05$ & $3.000 \mathrm{e}-05$ & $3.000 \mathrm{e}-05$ & $9.460 \mathrm{e}-02$ & $2.821 \mathrm{e}-01$ & $2.821 \mathrm{e}-01$ & $2.821 \mathrm{e}-01$ & 5.902 \\
\hline CCC & $1.608 \mathrm{e}-02$ & $1.608 \mathrm{e}-02$ & $1.608 \mathrm{e}-02$ & $1.608 \mathrm{e}-02$ & $1.608 \mathrm{e}-02$ & $1.608 \mathrm{e}-02$ & $6.783 \mathrm{e}-01$ & 22.526 \\
\hline Default & 0.000 & 0.000 & 0.000 & 0.000 & 0.000 & 0.000 & 0.000 & 100.000 \\
\hline
\end{tabular}

Table 5 shows the solution rating migration matrix after the first completion of the first type of optimization sub-process of the second step that seeks to further optimize the solution. The rating migration matrix entries of all rating categories were simultaneous optimized, with no additional delta-coefficients over and above the basic delta-coefficients. The solution has a squared error sum of less than $2.7 \mathrm{e}-08$, and figures 11 to 17 show that the reference and solution default probability term structures are virtually identical. Overall, significant differences between the reference rating migration matrix and solution rating migration matrix still exists, and rating category A and B have not yet significantly corrected. The results show that this sub-process is good at adjusting rating category rating migration matrix entries in response to each other, without significantly adjusting individual rating migration matrix entries per se. In figures 11 to 17 , the " $R$ " postscript depicts the reference term structure.

Table 5. Intermediate solution rating migration matrix

\begin{tabular}{|l|l|l|l|l|l|l|l|l|}
\hline & AAA & AA & A & BBB & BB & B & CCC & Default \\
\hline AAA & $9.131 \mathrm{e}-01$ & $8.059 \mathrm{e}-02$ & $2.596 \mathrm{e}-03$ & $2.596 \mathrm{e}-03$ & $1.029 \mathrm{e}-03$ & $4.494 \mathrm{e}-05$ & $2.964 \mathrm{e}-09$ & 0.000 \\
\hline AA & $9.579 \mathrm{e}-02$ & $7.538 \mathrm{e}-01$ & $1.488 \mathrm{e}-01$ & $7.441 \mathrm{e}-04$ & $7.440 \mathrm{e}-04$ & $2.875 \mathrm{e}-05$ & $1.000 \mathrm{e}-09$ & 0.000 \\
\hline A & $1.748 \mathrm{e}-05$ & $3.858 \mathrm{e}-01$ & $3.903 \mathrm{e}-01$ & $2.111 \mathrm{e}-01$ & $5.123 \mathrm{e}-03$ & $5.122 \mathrm{e}-03$ & $1.550 \mathrm{e}-03$ & 0.103 \\
\hline BBB & $2.180 \mathrm{e}-19$ & $7.239 \mathrm{e}-19$ & $9.378 \mathrm{e}-02$ & $8.198 \mathrm{e}-01$ & $7.907 \mathrm{e}-02$ & $2.807 \mathrm{e}-03$ & $2.436 \mathrm{e}-03$ & 0.212 \\
\hline BB & $1.228 \mathrm{e}-14$ & $9.495 \mathrm{e}-14$ & $1.952 \mathrm{e}-02$ & $6.405 \mathrm{e}-02$ & $8.047 \mathrm{e}-01$ & $9.045 \mathrm{e}-02$ & $9.195 \mathrm{e}-03$ & 1.209 \\
\hline B & $2.342 \mathrm{e}-15$ & $6.776 \mathrm{e}-15$ & $1.076 \mathrm{e}-14$ & $1.797 \mathrm{e}-02$ & $4.777 \mathrm{e}-02$ & $8.360 \mathrm{e}-01$ & $3.924 \mathrm{e}-02$ & 5.902 \\
\hline CCC & $1.026 \mathrm{e}-17$ & $1.164 \mathrm{e}-03$ & $1.273 \mathrm{e}-03$ & $1.784 \mathrm{e}-02$ & $1.787 \mathrm{e}-02$ & $1.305 \mathrm{e}-01$ & $6.060 \mathrm{e}-01$ & 22.526 \\
\hline Default & 0.000 & 0.000 & 0.000 & 0.000 & 0.000 & 0.000 & 0.000 & 100.000 \\
\hline
\end{tabular}




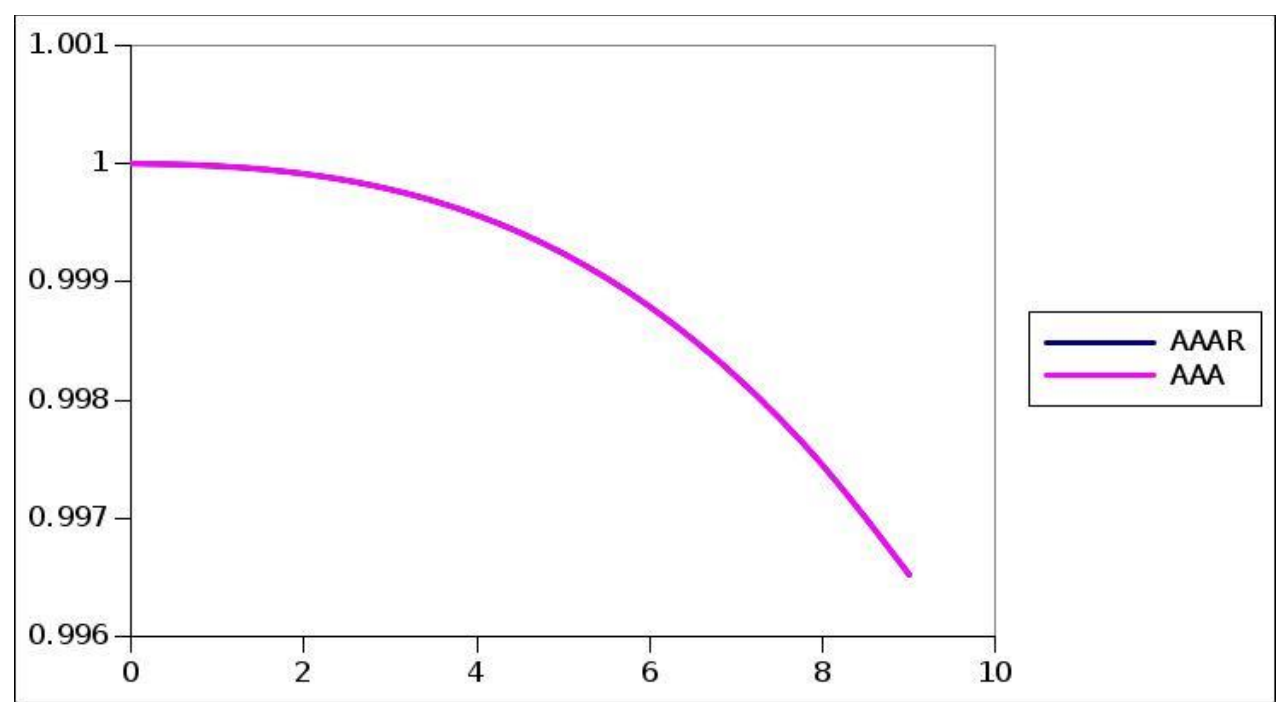

Figure 11. Reference and solution default probability term structures - AAA

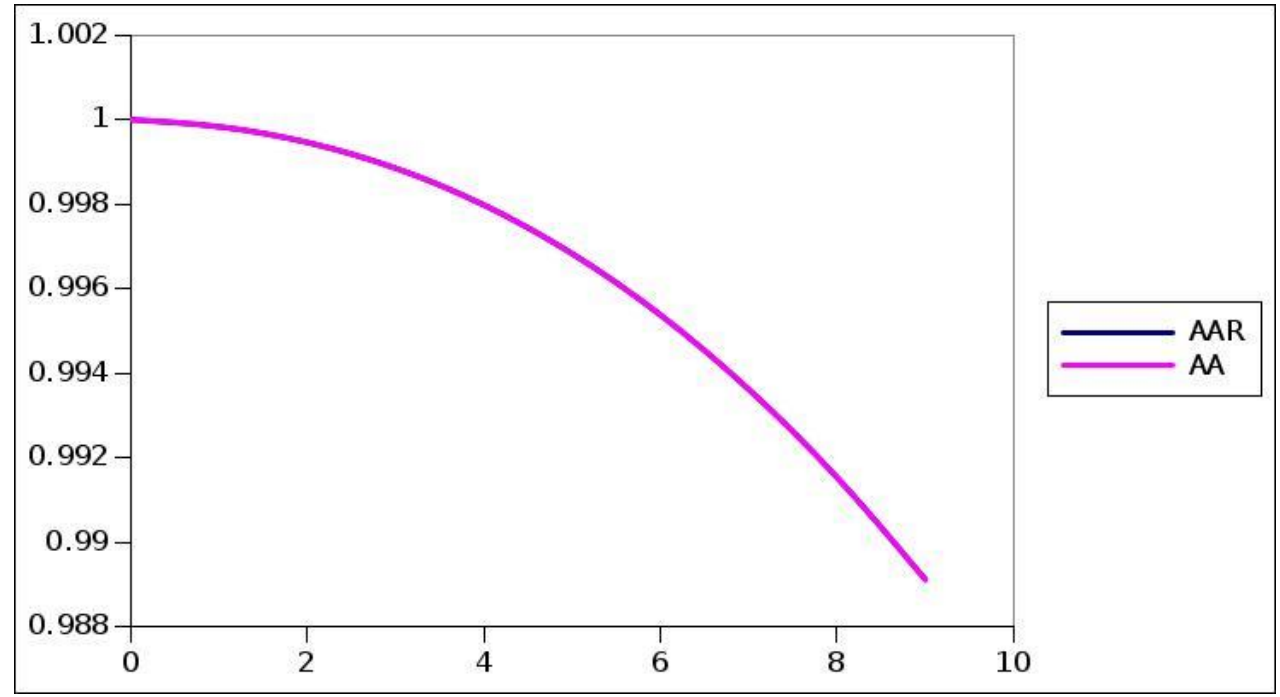

Figure 12. Reference and solution default probability term structures $-A A$

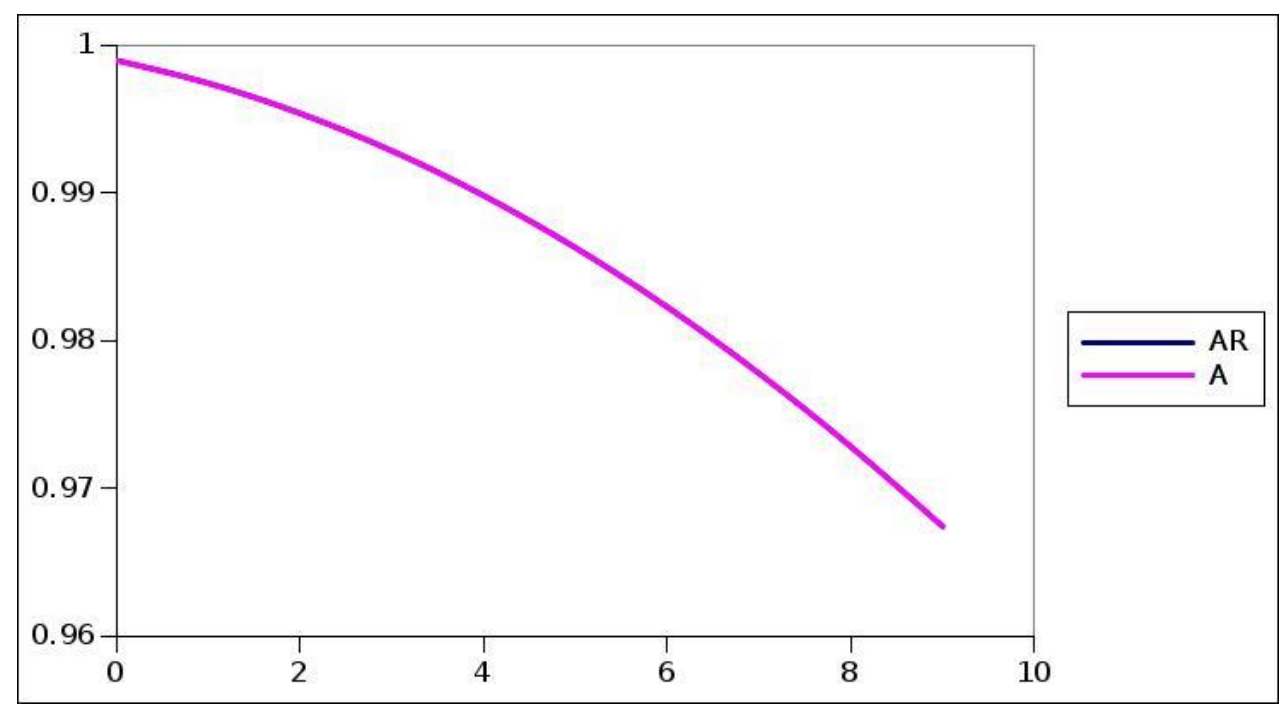

Figure 13. Reference and solution default probability term structures - A 


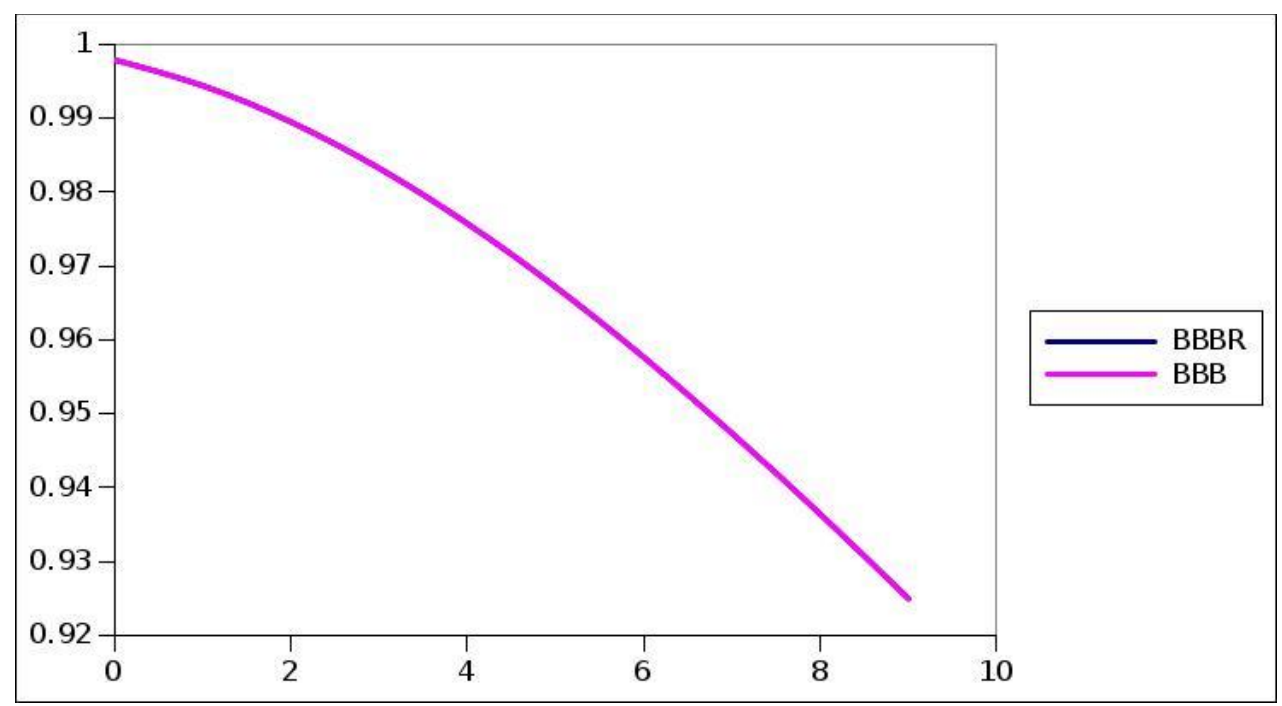

Figure 14. Reference and solution default probability term structures - BBB

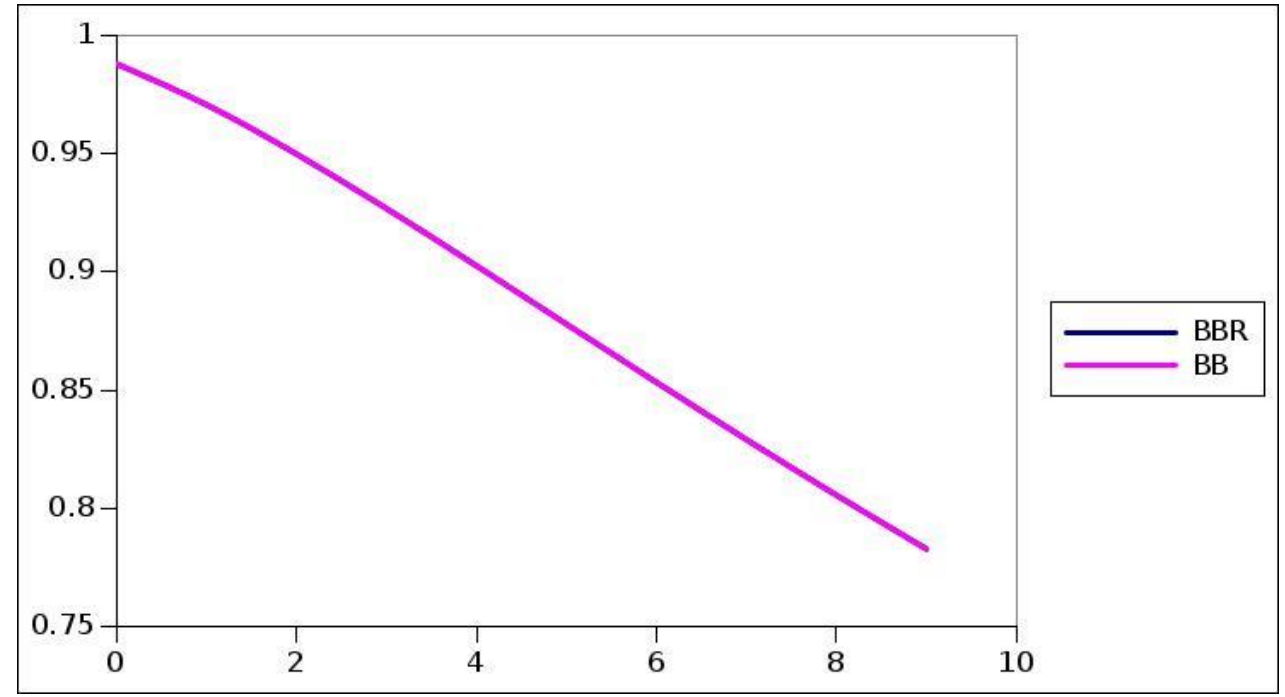

Figure 15. Reference and solution default probability term structures $-B B$

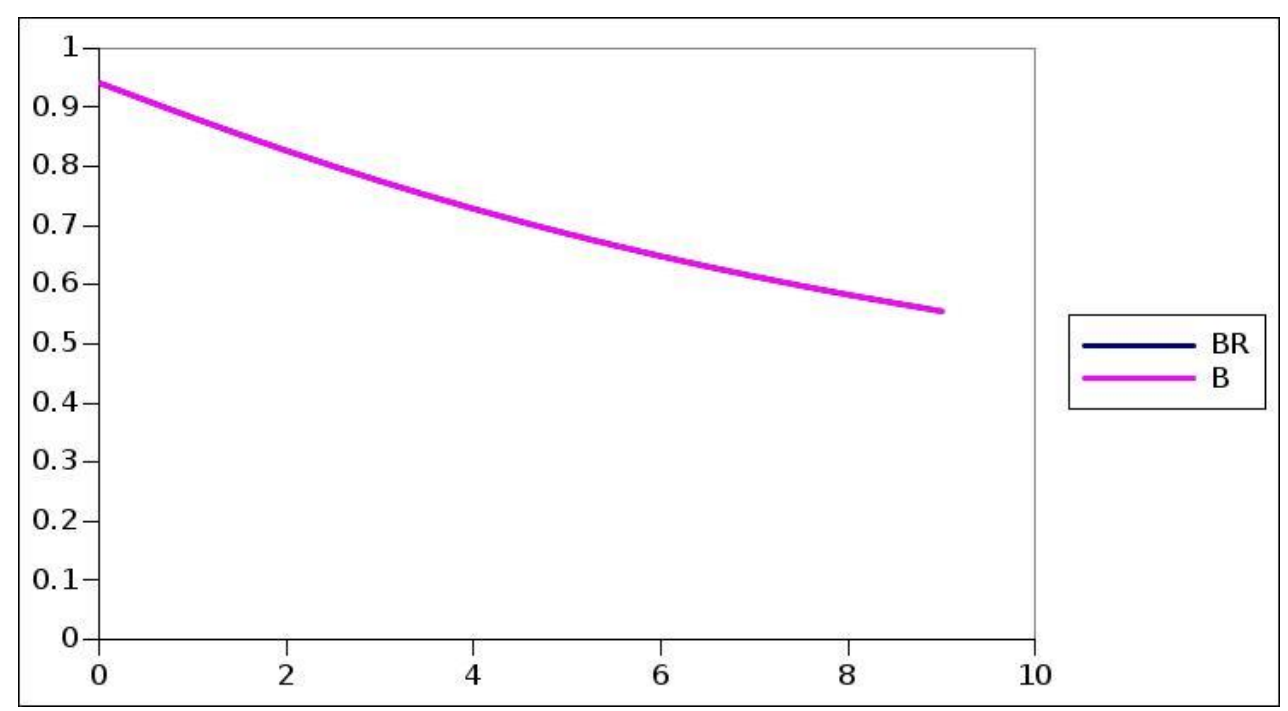

Figure 16. Reference and solution default probability term structures - B 


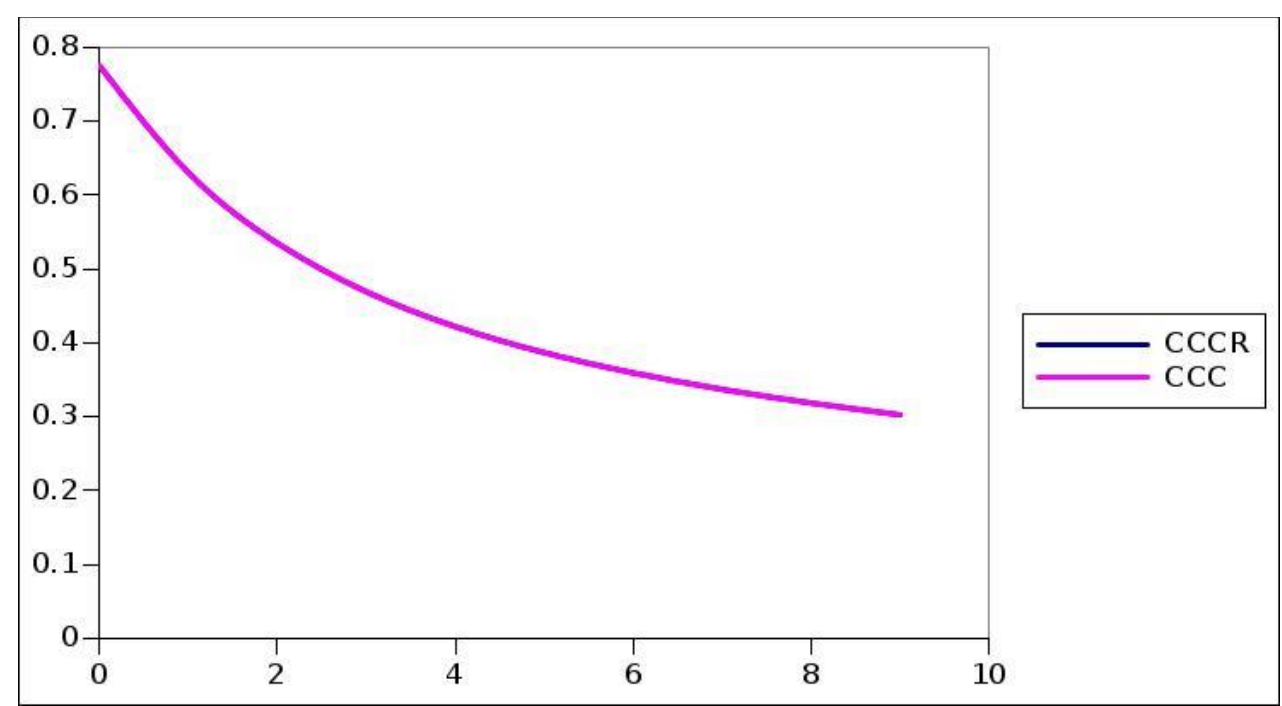

Figure 17. Reference and solution default probability term structures - CCC

Table 6 shows the solution rating migration matrix after the completion of a number of iterations of the first and second type of optimization sub-processes of the second step that seeks to further optimize the solution. At this point, the individual rating category rating migration matrix entries had already been sequentially and jointly optimized, a number of iterations. The solution has an error sum of less than 5e-16. Because of computation cost, the optimization was terminated at this point. Table 7 shows the absolute difference between the reference and solution rating migration matrix. Table 8 shows the maximum absolute difference between the reference and solution rating migration matrix of each rating category. Table 9 shows the sum of the absolute difference between the reference and solution rating migration matrix of each rating category. Table 10 shows the absolute error sum between the reference and modelled default probability term structures of each rating category. From table 8 , the highest rating migration probability error is $1.4011 \%$, and from table 9 , the highest rating migration probability error sum is $3.4372 \%$.

Table 6. Terminating solution rating migration matrix

\begin{tabular}{|l|l|l|l|l|l|l|l|l|}
\hline & AAA & AA & A & BBB & BB & B & CCC & Default \\
\hline AAA & 90.4983 & 8.79833 & 0.48167 & 0.11031 & 0.10961 & 0.00167 & 0.00015 & 0.000 \\
\hline AA & 0.71397 & 89.8189 & 8.90377 & 0.33068 & 0.15537 & 0.07478 & 0.00249 & 0.000 \\
\hline A & 1.28678 & 1.52366 & 90.6748 & 5.26536 & 0.7509 & 0.29095 & 0.10451 & 0.103 \\
\hline BBB & 0.04631 & 0.20946 & 6.02187 & 86.9229 & 5.30658 & 1.16364 & 0.11721 & 0.212 \\
\hline BB & 0.03347 & 0.03349 & 0.71615 & 7.67656 & 80.5527 & 8.78952 & 0.98913 & 1.209 \\
\hline B & 0.00577 & 0.09902 & 0.23989 & 0.44981 & 6.47086 & 82.7466 & 4.08604 & 5.902 \\
\hline CCC & 0.14832 & 0.14832 & 0.14832 & 1.26071 & 2.27524 & 12.8571 & 60.636 & 22.526 \\
\hline Default & 0.000 & 0.000 & 0.000 & 0.000 & 0.000 & 0.000 & 0.000 & 100.000 \\
\hline
\end{tabular}

Table 7. Solution, reference rating migration matrix absolute difference

\begin{tabular}{|l|l|l|l|l|l|l|l|l|}
\hline & AAA & AA & A & BBB & BB & B & CCC & Default \\
\hline AAA & 0.2907 & 0.5073 & 0.2343 & 0.0083 & 0.0076 & 0.0017 & 0.0002 & 0.0000 \\
\hline AA & 0.6110 & 1.4011 & 1.0528 & 0.2893 & 0.0524 & 0.0282 & 0.0025 & 0.0000 \\
\hline A & 0.3628 & 0.8373 & 0.6338 & 0.1756 & 0.0319 & 0.0170 & 0.0015 & 0.0000 \\
\hline BBB & 0.0463 & 0.1085 & 0.0839 & 0.0241 & 0.0046 & 0.0024 & 0.0002 & 0.0000 \\
\hline BB & 0.0335 & 0.0765 & 0.0571 & 0.0154 & 0.0027 & 0.0015 & 0.0001 & 0.0000 \\
\hline B & 0.0058 & 0.0150 & 0.0129 & 0.0042 & 0.0009 & 0.0004 & 0.0000 & 0.0000 \\
\hline CCC & 0.0797 & 0.0797 & 0.0797 & 0.0097 & 0.0002 & 0.0011 & 0.2280 & 0.0000 \\
\hline Default & 0.0000 & 0.0000 & 0.0000 & 0.0000 & 0.0000 & 0.0000 & 0.0000 & 0.0000 \\
\hline
\end{tabular}


Table 8. Rating category maximum rating migration matrix error (percentage)

\begin{tabular}{|c|c|c|c|c|c|c|}
\hline AAA & $\mathbf{A A}$ & A & BBB & BB & B & $\mathrm{CCC}$ \\
\hline 0.5073 & 1.4011 & 0.8373 & 0.1085 & 0.0765 & 0.0150 & 0.2280 \\
\hline
\end{tabular}

Table 9. Rating category total rating migration matrix error sum (percentage)

\begin{tabular}{|l|rr|r|r|r|r|r|r|}
\hline AAA & AA & A & BBB & BB & B & CCC \\
\hline & 1.0502 & 3.4372 & 2.0600 & 0.2699 & 0.1869 & 0.0391 & 0.4781 \\
\hline
\end{tabular}

Table 10. Absolute rating category reference versus modelled default probability term structure

\begin{tabular}{|l|l|l|l|l|l|l|}
\hline AAA & AA & A & BBB & BB & B & CCC \\
\hline $2.572120 \mathrm{E}-06$ & $4.267200 \mathrm{E}-07$ & $4.237900 \mathrm{E}-07$ & $3.603700 \mathrm{E}-07$ & $8.550100 \mathrm{E}-07$ & $1.306600 \mathrm{E}-07$ & $2.233700 \mathrm{E}-07$ \\
\hline
\end{tabular}

\section{Conclusion}

The study built on previous research that decomposes rating category default probability term structures from rating category interest rate term structures. A method to decompose rating migration matrices from market price data, via default probability term structures, was proposed and evaluated. A reference rating migration matrix was used to evaluate the method. Overall, the results are more than satisfactory, and the method promises to be accurate.

Future research can investigate the application of the method to market data. The outcome should be insightful in itself, and can be used to evaluate historical rating migration matrices commonly devised by rating agencies, and to form a better understanding of the default probability term structures embedded in market data.

\section{References}

Altman, E.I., 1989. Measuring corporate bond mortality and performance. The Journal of Finance, 44(4), pp. 909-922.

Altman, E.I., 1996. Rating Migration of Corporate Bonds: Comparative Results and Investor/Lender Implication. NYU Working Paper.

Altman, E.I. and Rijken, H.A., 2004. How rating agencies achieve rating stability. Journal of Banking \& Finance, 28(11), pp.2679-2714.

Amato, J.D. and Furfine, C.H., 2004. Are credit ratings procyclical?. Journal of Banking \& Finance, 28(11), pp.2641-2677.

Athanassakos, G. and Carayannopoulos, P., 2001. An empirical analysis of the relationship of bond yield spreads and macro economic factors. Applied Financial Economics, 11(2), pp.197-207.

Bangia, A., Diebold, F.X., Kronimus, A., Schagen, C. and Schuermann, T., 2002. Ratings migration and the business cycle, with application to credit portfolio stress testing. Journal of Banking \& Finance, 26(2), pp.445-474.

Barnard, B., 2016a. Interest Rate Term Structure Decomposition: An Axiomatic Structural Approach [online] Available at: https://papers.ssrn.com/abstract=2847737 [Accessed on 3 May 2017].

Barnard, B., 2016b. Interest Rate Term Structure Decomposition at the Instrument Level [online] Available at: https://papers.ssrn.com/abstract=2866995 [Accessed on 3 May 2017].

Barnard, B., 2017a. Rating Migration and Bond Valuation: Towards Ahistorical Rating Migration Matrices and Default Probability Term Structures [online] Available at: https://papers.ssrn.com/abstract=2893521 [Accessed on 3 May 2017].

Barnard, B., 2017b. Rating Migration and Bond Valuation: Ahistorical Interest Rate and Default Probability Term Structures [online] Available at: https://papers.ssrn.com/abstract=2948352 [Accessed on 3 May 2017].

Belkaoui, A., 1980. Industrial bond ratings: A new look. Financial Management, pp.44-51.

Benkert, C., 2004. Explaining credit default swap premia. Journal of Futures markets, 24(1), pp.71-92.

Blanco, R., Brennan, S. and Marsh, I.W., 2005. An empirical analysis of the dynamic relation between investment-grade bonds and credit default swaps. The Journal of Finance, 60(5), pp.2255-2281.

Campbell, J.Y. and Taksler, G.B., 2003. Equity volatility and corporate bond yields. The Journal of Finance, 58(6), pp.2321-2350. 
Cantor, R., Packer, F. and Cole, K., 1997. Split ratings and the pricing of credit risk. The Journal of Fixed Income, 7(3), pp.72-82.

Chan, K. and Jegadeesh, N., 2004. Market-based evaluation for models to predict bond ratings. Review of Pacific Basin Financial Markets and Policies, 7(02), pp.153-172.

Collin-Dufresne, P., Goldstein, R.S. and Martin, J.S., 2001. The determinants of credit spread changes. The Journal of Finance, 56(6), pp.2177-2207.

Das, S., and Tufano, P., 1995. Pricing Credit Sensitive Debt When Interest Rates, Credit Ratings, and Credit Spreads Are Stochastic. Journal of Financial Engineering, 5, 161-198.

Delianedis, G. and Geske, R.L., 2003, February. Credit risk and risk neutral default probabilities: information about rating migrations and defaults. In EFA 2003 annual conference paper (No. 962).

Duffee, G.R., 1999. Estimating the price of default risk. Review of Financial Studies, 12(1), pp.197-226.

Duffie, D. and Singleton, K.J., 1999. Modeling term structures of defaultable bonds. Review of Financial studies, 12(4), pp.687-720.

Ederington, L.H. and Goh, J.C., 1998. Bond rating agencies and stock analysts: who knows what when?. Journal of Financial and Quantitative Analysis, 33(04), pp.569-585.

Elton, J.E., 1999. Expected return, realized return and asset pricing tests. Journal of Finance, 4, pp.1199-1220.

Elton, E. J., Gruber, M. J., Agrawal, D. and Mann, C., 2001. Explaining the Rate Spread on Corporate Bonds. The Journal of Finance, 56(1), pp.247-278.

Elton, E.J., Gruber, M.J., Agrawal, D. and Mann, C., 2004. Factors affecting the valuation of corporate bonds. Journal of Banking \& Finance, 28(11), pp.2747-2767.

Eom, Y.H., Helwege, J. and Huang, J.Z., 2004. Structural models of corporate bond pricing: An empirical analysis. Review of Financial studies, 17(2), pp.499-544.

Ericsson, J., Jacobs, K. and Oviedo, R., 2009. The determinants of credit default swap premia. Journal of Financial and Quantitative Analysis, 44(1), pp.109-132.

Fama, E.F. and French, K.R., 1993. Common risk factors in the returns on stocks and bonds. Journal of financial economics, 33(1), pp.3-56.

Fei, F., Fuertes, A.M. and Kalotychou, E., 2012. Credit rating migration risk and business cycles. Journal of Business Finance \& Accounting, 39(1-2), pp.229-263.

Foss, G.W., 1995. Quantifying risk in the corporate bond markets. Financial Analysts Journal, 51(2), pp.2934.

Frydman, H. and Schuermann, T., 2008. Credit rating dynamics and Markov mixture models. Journal of Banking \& Finance, 32(6), pp.1062-1075.

Grandes, M. and Peter, M., 2005. How Important is Sovereign Risk in Determining Corporate Credit Spreads in Emerging Markets? The Case of Local Currency Bonds in South Africa. IMF Working Paper 217.

Geske, R.L. and Delianedis, G., 2001. The components of corporate credit spreads: Default, recovery, taxes, jumps, liquidity, and market factors [online] Available at: http://escholarship.org/uc/item/32x284q3 [Accessed on 3 May 2017].

Hamilton, D.T. and Cantor, R., 2004. Rating transition and default rates conditioned on outlooks. Journal of Fixed Income, 14(2), pp.54-70.

Hines, M.A., Ang, J.S. and Patel, K.A., 1975. Bond rating methods: Comparison and validation. The Journal of Finance, 30(2), pp.631-640.

Houweling, P., Mentink, A. and Vorst, T., 2005. Comparing possible proxies of corporate bond liquidity. Journal of Banking \& Finance, 29(6), pp.1331-1358.

Houweling, P. and Vorst, T., 2005. Pricing default swaps: Empirical evidence. Journal of International Money and Finance, 24(8), pp.1200-1225.

Huang, J.Z. and Huang, M., 2012. How much of the corporate-treasury yield spread is due to credit risk?. Review of Asset Pricing Studies, 2(2), pp.153-202.

Jarrow, R.A. and Turnbull, S.M., 1995. Pricing derivatives on financial securities subject to credit risk. The journal of finance, 50(1), pp.53-85.

Jarrow, R.A., Lando, D. and Turnbull, S.M., 1997. A Markov model for the term structure of credit risk spreads. Review of Financial studies, 10(2), pp.481-523.

Jarrow, R.A., Janosi, T. and Yildirim, Y., 2002. Estimating expected losses and liquidity discounts implicit in debt prices. Journal of Risk, 5(1), pp.1-38.

Kadam, A. and Lenk, P., 2008. Bayesian inference for issuer heterogeneity in credit ratings migration. Journal of Banking \& Finance, 32(10), pp.2267-2274.

Kaplan, R.S. and Urwitz, G., 1979. Statistical models of bond ratings: A methodological inquiry. Journal of business, pp.231-261. 
Kim, H., K. Ramaswamy, and S. Sunderesan, 1993. Valuation of Corporate Fixed-Income Securities. Financial Management (Special issue on financial distress), 22(3), pp.60-78.

Kumar, K. and Haynes, J.D., 2003. Forecasting credit ratings using an ANN and statistical techniques. International journal of business studies, 11(1), pp.91-108.

Lando, D. and Skødeberg, T.M., 2002. Analyzing rating transitions and rating drift with continuous observations. Journal of banking \& finance, 26(2), pp.423-444.

Longstaff, Francis A., and Eduardo S. Schwartz, 1995, A simple approach to valuing risky fixed and floating rate debt. Journal of Finance, 50, pp.789-819.

Longstaff, F.A., Mithal, S. and Neis, E., 2005. Corporate yield spreads: Default risk or liquidity? New evidence from the credit default swap market. The Journal of Finance, 60(5), pp.2213-2253.

Manzoni, K., 2004. Modeling Eurobond credit ratings and forecasting downgrade probability. International Review of Financial Analysis, 13(3), pp.277-300.

Marciniak, M., 2006. Yield curve estimation at the National Bank of Poland; Bank i Kredyt; 10; p. 52-74

Merton, R., 1974. On the pricing of corporate debt: the risk structure of interest rates. Journal of Finance, (May), 29(2), pp.449-470.

Nelson, C.R. and Siegel, A.F., 1987. Parsimonious modeling of yield curves. Journal of business, pp.473-489.

Nickell, P., Perraudin W. and Varotto, S., 2000. Stability of Rating Transitions. Journal of Banking \& Finance, 24, pp.203-227.

Norden, L. and Weber, M., 2009. The co-movement of credit default swap, bond and stock markets: An empirical analysis. European financial management, 15(3), pp.529-562.

Wang, Z., 2004. Financial ratio selection for default-rating modeling: a model-free approach and its empirical performance. Journal of Applied Finance, 14(1), pp.20-35.

Weistroffer, C., Speyer, B., Kaiser, S. and Mayer, T., 2009. Credit default swaps. Deutsche bank research.

Zhu, H., 2006. An empirical comparison of credit spreads between the bond market and the credit default swap market. Journal of Financial Services Research, 29(3), pp.211-235. 